\title{
RESEARCH
}

Open Access

\section{Interleukin-6 actions in the hypothalamus protects against obesity and is involved in the regulation of neurogenesis}

Vanessa C. Bobbo 1,2, Daiane F. Engel ${ }^{2}$, Carlos Poblete Jara ${ }^{1,2}$, Natalia F. Mendes ${ }^{1,2}$, Roberta Haddad-Tovolli2, Thais P. Prado ${ }^{1,2}$, Davi Sidarta-Oliveira², Joseane Morari ${ }^{2}$, Licio A. Velloso ${ }^{2}$ (D) and Eliana P. Araujo ${ }^{1,2^{*}}$

\begin{abstract}
Background: Interleukin-6 (IL6) produced in the context of exercise acts in the hypothalamus reducing obesityassociated inflammation and restoring the control of food intake and energy expenditure. In the hippocampus, some of the beneficial actions of IL6 are attributed to its neurogenesis-inducing properties. However, in the hypothalamus, the putative neurogenic actions of IL6 have never been explored, and its potential to balance energy intake can be an approach to prevent or attenuate obesity.

Methods: Wild-type (WT) and IL6 knockout (KO) mice were employed to study the capacity of IL6 to induce neurogenesis. We used cell labeling with Bromodeoxyuridine (BrdU), immunofluorescence, and real-time PCR to determine the expression of markers of neurogenesis and neurotransmitters. We prepared hypothalamic neuroprogenitor cells from KO that were treated with IL6 in order to provide an ex vivo model to further characterizing the neurogenic actions of IL6 through differentiation assays. In addition, we analyzed single-cell RNA sequencing data and determined the expression of IL6 and IL6 receptor in specific cell types of the murine hypothalamus.

Results: IL6 expression in the hypothalamus is low and restricted to microglia and tanycytes, whereas IL6 receptor is expressed in microglia, ependymocytes, endothelial cells, and astrocytes. Exogenous IL6 reduces diet-induced obesity. In outbred mice, obesity-resistance is accompanied by increased expression of IL6 in the hypothalamus. IL6 induces neurogenesis-related gene expression in the hypothalamus and in neuroprogenitor cells, both from WT as well as from $\mathrm{KO}$ mice.

Conclusion: IL6 induces neurogenesis-related gene expression in the hypothalamus of WT mice. In KO mice, the neurogenic actions of IL6 are preserved; however, the appearance of new fully differentiated proopiomelanocortin (POMC) and neuropeptide Y (NPY) neurons is either delayed or disturbed.
\end{abstract}

Keywords: Cytokine, Metabolism, Neuron, Astrocyte, Brain, Diabetes

\footnotetext{
* Correspondence: earaujo@unicamp.br

${ }^{1}$ Nursing School, University of Campinas, Campinas, Brazil

${ }^{2}$ Laboratory of Cell Signaling, University of Campinas, Rua Cinco de Junho,

350, Cidade Universitária, Campinas, SP 13083-877, Brazil
}

(C) The Author(s). 2021 Open Access This article is licensed under a Creative Commons Attribution 4.0 International License, which permits use, sharing, adaptation, distribution and reproduction in any medium or format, as long as you give appropriate credit to the original author(s) and the source, provide a link to the Creative Commons licence, and indicate if changes were made. The images or other third party material in this article are included in the article's Creative Commons licence, unless indicated otherwise in a credit line to the material. If material is not included in the article's Creative Commons licence and your intended use is not permitted by statutory regulation or exceeds the permitted use, you will need to obtain permission directly from the copyright holder. To view a copy of this licence, visit http://creativecommons.org/licenses/by/4.0/ The Creative Commons Public Domain Dedication waiver (http://creativecommons.org/publicdomain/zero/1.0/) applies to the data made available in this article, unless otherwise stated in a credit line to the data. 


\section{Background}

Interleukin-6 (IL6) is a rather unique cytokine that exerts pleiotropic actions in distinct organs and systems [1, 2]. Factors such as magnitude of production, duration of response and site of action may have either protective or damaging impact on organism health [3, 4]. For example, the rapid activation of IL6 response during early infection has critical role in host protection [5-7], whereas in chronic inflammatory diseases and obesityassociated metabolic inflammation, the enduring actions of IL6 promote structural and functional losses that may result in irreversible damage [8-12].

One remarkable advance in the understanding of the beneficial actions of IL6 was the characterization of its production by the exercised muscle [13]. Differently of the pattern of production in infectious and chronic inflammatory conditions, during exercise, IL6 is produced for a short period of time, independently of a previous stimulation by tumor necrosis factor-alpha (TNF $\alpha$ ) and accompanied by only moderate/low increase of other inflammatory substances [14]. This particular mode of IL6 production has been shown to mediate some of the health promoting actions of exercise, such as increasing systemic insulin action [15-17], reducing hepatic steatosis [18], and reducing hepatic glucose production [17].

The brain is an important site of action of IL6. Studies have shown that exercise-induced IL6 can attenuate memory impairment in models of Alzheimer's disease $[19,20]$, whereas in the hypothalamus, IL6 produced in response to exercise can reduce diet-induced inflammation and correct the abnormal regulation of food intake $[21,22]$. The reduction of neuroinflammation is one of the mechanisms mediating the actions of IL6 in models of exercise [21]; however, recent studies have shown that induction of neurogenesis is yet another important mechanism mediating the actions of IL6 improving cognition in models of traumatic brain injury and Alzheimer's disease [23, 24].

Most studies evaluating adult neurogenesis have focused on the subventricular and subgranular zones (SVZ and SGZ, respectively), which provide new neurons for these specific regions, as well as for neighboring areas, such as striatum in humans $[25,26]$.

However, evidence suggests that replacement of hypothalamic neurons during life relies on local production, thus placing the hypothalamus as an autonomous adult neurogenesis niche $[27,28]$. In concern with the hypothalamic functions controlling food intake and energy homeostasis, stimuli such as leptin and insulin, as well as nutrients, have been shown to regulate hypothalamic neurogenesis [28-31]. As IL6 produced during exercise is known to mitigate diet-induced hypothalamic dysfunction [21] and, considering that IL6 neurogenic potential has been shown in other neurogenic niches of the brain, here, we decided to evaluate the putative neurogenic actions of IL6 in the hypothalamus.

\section{Methods \\ Experimental animals}

Six- to 12-week-old male Swiss mice and 8-week-old male and female C57BL/6J mice (WT; Jackson Laboratory stock \#000664) were obtained from the University of Campinas Animal Facility. Male and female, 8-weekold interleukin-6 knockout (KO; C57BL6/J $\mathrm{KO}^{\mathrm{il6-l}-}$; Jackson Laboratory stock \# 002254) were obtained from the Ribeirão Preto Medical School. Male and female,

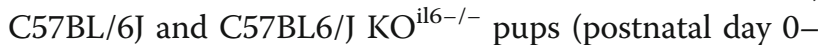
7) were obtained from the University of Campinas Animal Facility. All mice were kept in individual cages at 21 $\pm 0.5{ }^{\circ} \mathrm{C}$, in $12 / 12-\mathrm{h}$ light/dark cycle, with water and chow available ad libitum. In all experiments, control and intervention group mice were submitted to the same experimental settings.

\section{Experimental protocol In vivo protocol \#1}

Swiss mice were randomly separated into two groups: IL6 treatment or vehicle (saline). Thereafter, mice were fed a HFD for 2 weeks as described at the end of this paragraph (schematically illustrated in Fig. 1A). To determine caloric intake, the number of daily calories ingested by each mouse was divided by its weight in grams (Kcal/g/day); this approach was adopted because of the considerable variability in body mass among mice. The macronutrient composition of standard chow was $20 \mathrm{~g} \%$ protein, $76 \mathrm{~g} \%$ carbohydrate, and $4 \mathrm{~g} \%$ fat, resulting in energy value of $17.5 \mathrm{~kJ} / \mathrm{g}$; the macronutrient composition of HFD was $20 \mathrm{~g} \%$ protein, $45 \mathrm{~g} \%$ carbohydrate, and $35 \mathrm{~g} \%$ fat, resulting in energy value of $24.1 \mathrm{~kJ} / \mathrm{g}$.

\section{In vivo protocol \#2}

Another set of Swiss mice were fed a HFD for $24 \mathrm{~h}$ and then defined as $\mathrm{H}$ (25\% of animals that consumed highest amount of diet) or L ( $25 \%$ of animals that consumed lowest amount); thereafter, mice were euthanized and the hypothalami were collected for gene expression analysis (schematically illustrated in Fig. 3A).

\section{In vivo protocol \#3}

In order to perform central delivery of palmitate (30 $\mu \mathrm{M}, 2 \mu \mathrm{l}$; Sigma) or vehicle (saline), Swiss mice were submitted to a single stereotaxic injection in the third ventricle under xylazine $(10 \mathrm{mg} / \mathrm{kg}$, ip) and ketamine (100 mg/kg, ip) anesthesia. The coordinates from Bregma were as follows: anteroposterior, $0.0 \mathrm{~mm}$; lateral, $0.0 \mathrm{~mm}$; and depth, $4.5 \mathrm{~mm}[32,33]$. According to a time-course, mice were euthanized and the hypothalami were collected for gene expression analysis. 


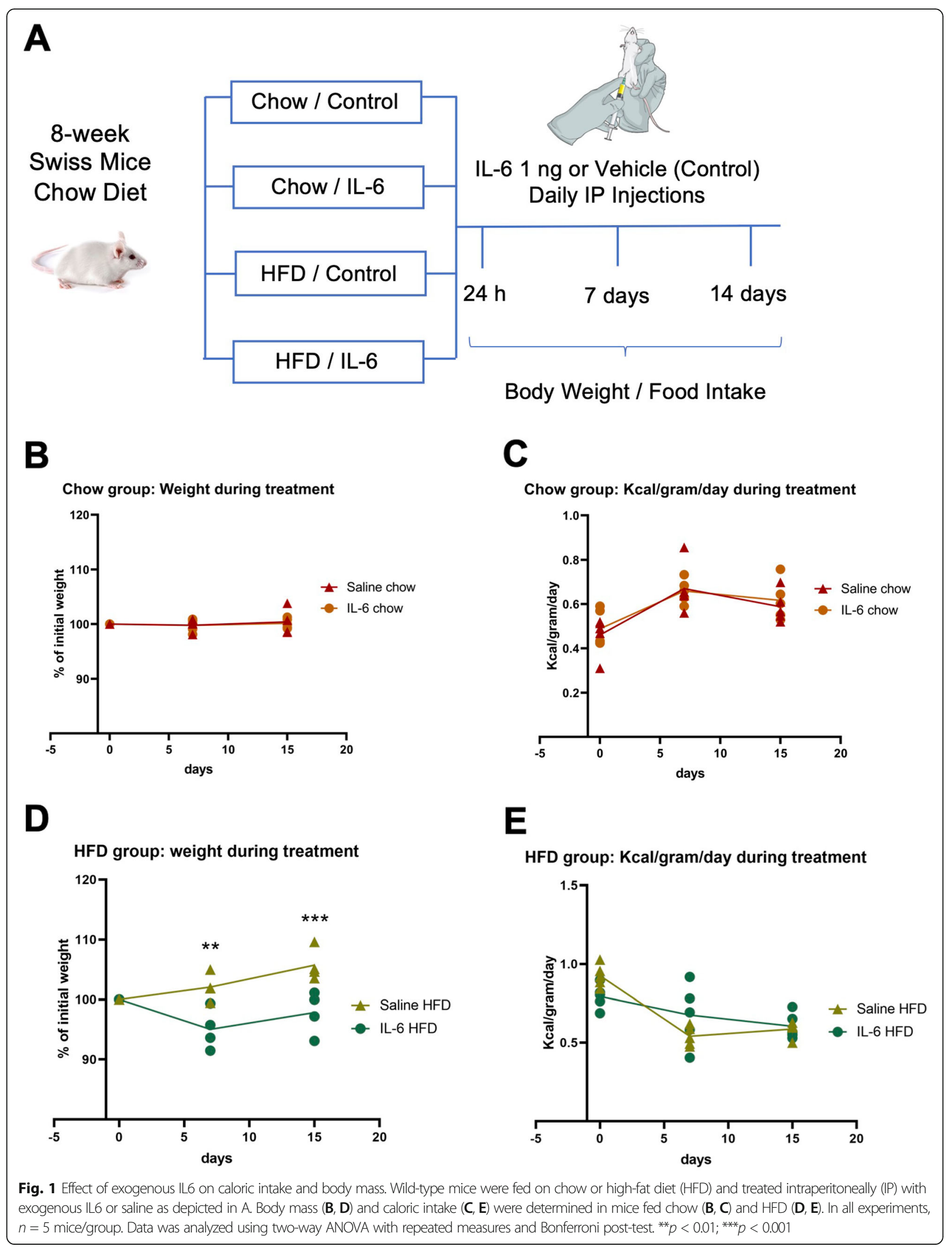




\section{In vivo protocol \#4}

C57BL/6J mice were treated with vehicle (saline) or recombinant IL6 (Sigma) (1 ng ip, once a day, for up to 7 days, proliferation assay, or 14 days, survival assay). Bromodeoxyuridine (BrdU; Sigma) was used to evaluate cell proliferation. BrdU is a thymidine analog that is incorporated into the DNA double-helix during the S-phase of the cell cycle, and thus labels actively proliferating cells [34]. Mice received BrdU (0.1 M PBS, pH = 7.2; $50 \mathrm{mg} /$ $\mathrm{Kg} 2 \mathrm{x}$ day ip for 7 days concomitant with IL6) and were euthanized $24 \mathrm{~h}$ after the last injection (proliferation assay, schematically illustrated in Fig. 4A) or 14 days after the last injection (survival assay, schematically illustrated in Fig. 4D).

\section{In vivo protocol \#5}

Swiss mice were treated with a single injection of vehicle (saline) or recombinant IL6 (Sigma) (1 ng ip) at different time points $(8 \mathrm{~h}, 6 \mathrm{~h}, 4 \mathrm{~h}, 2 \mathrm{~h}$ prior to extraction). Thereafter, mice were euthanized and the hypothalami collected for gene expression analysis (schematically illustrated in Fig. 5A).

\section{In vivo protocol \#6}

Adult IL6 knockout (KO) mice fed on chow were compared to the respective WT, C57BL/6J controls. For that, we determined body mass and blood IL-6 levels at baseline conditions and $4 \mathrm{~h}$ after treatment with recombinant IL6 (Sigma) (1 ng ip) and hypothalamic gene expression analysis in baseline conditions.

\section{Immunofluorescence staining}

Mice were deeply anesthetized with a solution of xylazine (10 mg/kg, ip) and ketamine (100 mg/kg, ip) and perfused through the left cardiac ventricle with $0.9 \%$ saline solution, followed by $4 \%$ paraformaldehyde (PFA) in $0.1 \mathrm{M}$ PBS ( $\mathrm{pH} 7.4)$. After perfusion, the brains were removed, post-fixed in the same fixative solution for $24 \mathrm{~h}$ at room temperature (RT), and immersed in a $30 \%$ sucrose solution in PBS at $4{ }^{\circ} \mathrm{C}$. Serial coronal sections (20 $\mu \mathrm{m})$ of hypothalami were obtained with a cryostat (LEICA Microsystems, CM1860). In order to determine cell proliferation and survival in the hypothalamic ventricular zone and parenchyma, a series of one-in-four free-floating sections were processed for detection of the BrdU immunoreactivity. Differentiation was assessed by BrdU/neuronal nuclei (NeuN) double labeling. Briefly, after DNA denaturation in $2 \mathrm{~N} \mathrm{HCl}$ at room temperature (RT) for $1 \mathrm{~h}$ and pre-incubation with $10 \%$ blocking solution (0.1M PBS with $10 \%$ normal goat or donkey serum and $0.2 \%$ Triton $\mathrm{X}-100)$, sections were incubated overnight at $4{ }^{\circ} \mathrm{C}$ in rat anti-BrdU (1:200; Ab6326) and mouse anti-NeuN (1:200; MAB377C3; Cy3 Conjugate) primary antibodies. The sections were then incubated with secondary antibody goat anti-rat FITC (1:200; sc2011) for $2 \mathrm{~h}$ at RT. All sections were mounted, cover slipped with Fluor Mount (Sigma), and stored at 4 ${ }^{\circ} \mathrm{C}$. The morphological analyses were performed on coded slides, with the executing researcher blinded to the experimental group. The total numbers of BrdUimmunopositive cells in the HVZ and PA were estimated by manually counting all positive cells. From all sections containing the hypothalamus (1.06 to $2.30 \mathrm{~mm}$ posterior to Bregma), one-in-four series of sections were used for the analysis. The results were expressed as the counted number of labeled cells multiplied by 4 (the section interval), and the resulting number was corrected using the Abercrombie formula. Newly formed neurons (BrdU/NeuN-positive cells) were analyzed in one-in-four series of sections by immunofluorescence double staining [35]. The results were expressed as the counted number of labeled cells multiplied by 4 (the section interval), and the resulting number was corrected using the Abercrombie formula. The amount of BrdU/NeuNpositive cells was expressed as percentages. A maximum of 50 BrdU-labeled cells per mouse were randomly selected for analysis of co-labeling with NeuN. Double labeling was confirmed by three-dimensional orthogonal reconstruction (Imaje J software) of z-series (average of 18 images per series) of confocal microscopy covering the entire nucleus (or cell) of interest (confocal microscope Upright LSM780-NLO) in sequential scanning mode to avoid cross-bleeding between channels. Nuclei diameter was estimated using the Fiji software, as previously described [36]. Only cells that presented a typical aspect of NeuN surrounding the nucleus were considered. The representative images are the stack of the $\mathrm{z}$ project of all images obtained within the $20 \mu \mathrm{m}$ section. In order to avoid overestimation of cell count, we performed Abercrombie Correction according to the formula $N=n \times(T /(T+\mathrm{D})$, where $n=$ cell counting, $T=$ section thickness $(20 \mu \mathrm{m})$, and $D=$ estimated diameter of cell nuclei (approx. $15 \mu \mathrm{m}$ ), as described elsewhere $[37,38]$.

\section{Serum IL-6 determination}

Blood samples were collected immediately after decapitation using a tube with citrate. Plasma was separated by centrifugation $(1100 \times g)$ for $15 \mathrm{~min}$ at $4{ }^{\circ} \mathrm{C}$ and stored at - $80{ }^{\circ} \mathrm{C}$ until assay. IL- 6 concentrations were determined using a commercially available Enzyme Linked Immunosorbent Assay kit, according to manufacturer instructions (Mouse IL-6 DuoSet ELISA, R\&D Systems).

\section{Postnatal neurosphere culture}

Postnatal day 0-7 pups were euthanized, their brains immediately removed, and the hypothalamus microdissected. Tissue fragments were repeatedly dissociated 
with a Pasteur pipette in PBS with $5.5 \mathrm{mM}$ glucose, 100 $\mathrm{U} / \mathrm{mL}$ penicillin, and $100 \mathrm{mg} / \mathrm{mL}$ streptomycin. Cells were suspended in $5 \mathrm{~mL}$ of proliferation media: Dulbecco's modified Eagle's medium (DMEM)-F12/Glutamax (Gibco) supplemented with growth factors $(10 \mathrm{ng} / \mathrm{mL}$ human basic fibroblast growth factor, bFGF, and $10 \mathrm{ng} /$ $\mathrm{mL}$ epidermal growth factor, EGF, sigma) $100 \mathrm{U} / \mathrm{mL}$ penicillin, $100 \mathrm{mg} / \mathrm{mL}$ streptomycin, and $1 \%$ B27 supplement. The floating neurospheres were allowed to grow in uncoated $25-\mathrm{cm}^{2}$ flasks in a humidified incubator with a $5 \% \mathrm{CO}_{2}$ atmosphere. On culture day 7 , neurospheres were collected by centrifugation, mechanically dissociated using a pipette, and plated using approximately 100,000 cells per well in fresh proliferation medium, onto Poly-L-Lysine (PLL; Sigma)-coated 12 well culture plates for RNA extraction or glass coverslips for immunocytochemistry. Once the monolayer reached confluence, cell differentiation was induced by switching proliferation media for differentiation media: neurobasal medium (Gibco) supplemented with 1\% B27 (Invitrogen), $500 \mathrm{mM} / \mathrm{L}$-Glutamine (Sigma), and 50 units $/ \mathrm{mL}$ penicillin/streptomycin (Life Technologies), without growth factors. The differentiation protocol was carried for 5 to 14 days to assess the differences between WT and $\mathrm{KO}$ mice and upon IL-6 $(2 \mathrm{pg} / \mathrm{ml}, 20 \mathrm{pg} / \mathrm{ml}, 200 \mathrm{pg} /$ $\mathrm{mL}$, and $2 \mathrm{ng} / \mathrm{mL}$ ) treatment over the expression of cell stemness and differentiation markers.

\section{Immunocytochemistry}

Cover slips containing differentiated neurospheres were fixed with 4\% PFA in $0.1 \mathrm{M}$ PBS for $10 \mathrm{~min}$ at RT. After washing with PBS, the cells were incubated in blocking solution (10\% normal donkey serum in $0.1 \mathrm{M}$ PBS containing $0.2 \%$ Triton $\mathrm{X}-100)$ for $1 \mathrm{~h}$ at RT. The cells were then incubated in fresh blocking solution (3\% normal donkey serum) containing rabbit anti-DCX (1:200; Cell Signaling 4,604), rabbit anti-MAP2 (1:200; ab32454), or anti-GFAP Cy3 (1:2000; ab49874) overnight at $4{ }^{\circ} \mathrm{C}$. The cells were washed three times with PBS and incubated in blocking solution containing donkey anti-rabbit FITC (1: 500; ab6798) for $1 \mathrm{~h}$ at RT, followed by DAPI for $10 \mathrm{~min}$ at RT. Following another three PBS washes, the slides were mounted using fluorescence mounting medium before image capturing on fluorescence microscopy (Olympus BX41). The results of immunopositive cells represent the average of 4 cover slips per experimental replicate, where 4-5 fields were imaged per cover slip and averaged. The number of immunopositive cells was quantified per image using the ImageJ software and are expressed as percentage relative to total nuclei.

\section{RNA extraction and quantitative real-time PCR}

RNA samples were prepared using TRIzol (Invitrogen) according to the manufacturer's recommendations.
Spectrophotometry was employed for RNA quantification. For each sample, $2 \mu \mathrm{g}$ of RNA was employed for the synthesis of complementary DNA (cDNA) using the High Capacity cDNA Reverse Transcription Synthesis kit (Applied Biosystems). Real-time PCR reactions were run using the TaqMan system (Applied Biosystems). Analyses were run using $4 \mu \mathrm{L}(10 \mathrm{ng} / \mu \mathrm{L}) \mathrm{cDNA}, 0.625$ $\mu \mathrm{L}$ primer/probe solution, $1.625 \mu \mathrm{L} \mathrm{H}_{2} \mathrm{O}$, and $6.25 \mu \mathrm{L}$ 2X TaqMan Universal MasterMix. GAPDH (Mm99999915_g1) was employed as a reference gene. Gene expression was obtained using the StepOne Plus System software (Applied Biosystems). As negative control, no retrotranscriptase was added. All primers used in the study (Supplementary Table 1) were certified for efficiency and specificity, as declared by the manufacturers. Nevertheless, we further validated the primers by amplifying the cDNA of each sample in triplicates at six different concentrations (3-fold serial dilutions). Both the primers for the target genes and reference gene were tested. The efficiency of the system was calculated using the formula: $E=10$ (-1/slope) -1 . The quantification method used for the calculations of the data was the $2^{-\mathrm{dct}}$ method. Then, the average data from the control group was considered as 1 , and other groups were relative to control. This was the fold change calculation used.

\section{Single-cell RNA sequencing data extraction and processing}

scRNAseq data from the adult mouse arcuate nucleus was obtained from GEO (GSE93374). Data analysis was performed with Seurat v3.2.2 [39], a scRNAseq data analysis toolkit in R. Data was normalized with SCTransform, a negative binomial normalization approach to scRNAseq data [40]. We then selected top 5000 differentially expressed genes (DEGs) with a dispersion method and used these in the computation of dbMAP. dbMAP estimates data structure from a series of random walks by employing adaptive multiscale diffusion maps for a first round of dimensional reduction which is followed by an adapted UMAP implementation on the multiscale diffusion components and is available in python (https:// doi.org/10.2139/ssrn.3582067). Plots of dbMAP embeddings colored by annotated cell type were obtained with the function DimPlot of Seurat, with cell groupings from the original data report.

For Bayesian normalization of raw counts data, BASiCS (Bayesian Analysis of Single-Cell Sequencing data) was employed. Briefly, BASiCS is an integrated Bayesian hierarchical model that simultaneously performs data normalization and technical noise quantification to propagate statistical uncertainty. We used BASiCS new implementation which does not require the use of Spikeins for data normalization and evaluates probabilistic 
consistency across batches instead [41]. Briefly, a Markov Chain Monte Carlo was constructed with the $B A$ SiCS_MCMC function of the BASiCS package in $\mathrm{R}$ with default recommended parameters and used for reestimation of a denoised counts matrix with the $B A$ SiCS_DenoisedCounts function. All processed data and custom code used for analysis are available upon request.

\section{Visualization of gene expression}

With the exception of plots from Suppl. Fig. 2, BASiCS probabilistic denoised gene expression was used for visualization. For dbMAP plots we used the DimPlot and FeaturePlot functions within Seurat, with the blend parameter set to TRUE for visualization of gene coexpression. All other visualizations were carried out with the Scanpy plotting API (https://doi.org/10.1186/s13059017-1382-0 ) after conversion to a h5ad AnnData object via SeuratDisk, an auxiliary Seurat package. Marker genes for main cell types defined on the original study were found via the Scanpy default workflow through Wilcoxon rank-sum tests and visualized in a heatmap.

\section{Statistical analysis}

For all experiments, sample size was determined taking into consideration recommendations published elsewhere [42]. Data were analyzed using GraphPad Prism version 8.0.1. The statistical analyses were carried out using unpaired two-tailed Student's $t$-test, one-way analysis of variance (ANOVA) with Tukey's multiple comparison test, Kruskall-Wallis test with Dunn's multiple comparison test, or two-way ANOVA with repeated measures and Bonferroni post-test when appropriate. Outliers were identified using Grubbs test. Data are presented as means \pm standard error of the mean (SEM). A $p$ value $<0.05$ was considered to be statistically significant. Details of statistical analysis of all experiments described in this study are presented in Supplementary Table 2.

\section{Results}

\section{Exogenous IL6 protects against diet-induced body mass} gain

The consumption of large portions of dietary fats can induce hypothalamic inflammation, affecting the function and viability of critical neurons involved in the control of caloric intake and energy expenditure [43, 44]. Here, we asked if exogenous IL6 could act as a protective factor against diet-induced obesity. For that, 8-week mice were randomly divided into four groups as depicted in Fig. 1A (described in "In vivo protocol \#1"). In mice fed chow, exogenous IL6 resulted neither in body mass (Fig. 1B) nor caloric ingestion (Fig. 1C) changes. However, in mice fed HFD, IL6 protected against body mass gain
(Fig. 1D), which occurred independently of changes in caloric intake (Fig. 1E). The combined analysis of all groups confirmed the effect of IL6 protecting mice from diet-induced obesity (Suppl. Fig. 1A) without affecting caloric intake (Suppl. Fig. 1B).

\section{IL6 and its canonical receptor are expressed in the arcuate nucleus of the hypothalamus of adult mice} Using dbMAP [45] as a dimensional reduction method for high-resolution visualization, we analyzed 20,921 public single-cell transcriptomes from the arcuate nucleus and median eminence of adult mice [46] into a comprehensive landscape of cellular heterogeneity. In this embedding (Fig. 2A), cells are colored by their original main cell type annotations. IL6 (Il6) mRNA was expressed in only a few cells, classified as microglia and tanycytes (Suppl. Fig. 2A). To exclude the possibility that Il6-expressing cells could be a result of random methodological noise, we performed a Bayesian normalization procedure in order to obtain a denoised, probabilisticderived data matrix with BASiCS [47] and show that these cells indeed express barely detectable $I l 6$, at much lower levels than corresponding marker genes (Suppl. Fig. 2A). Differently than $I l 6$, its canonical receptor encoded by Il6ra and its trans-signaling receptor encoded by Il6st are abundantly expressed across different cell types (Fig. 2B, C and Suppl. Fig. 2B-2C). Il6ra is preferentially expressed in $C x 3 c r 1+$ perivascular macrophages/microglia (cluster a07), endothelial cells (cluster a03), and ependymocytes (cluster a09), whereas Il6st is broadly expressed in tanycytes and arcuate neurons, as well as neurotrophic receptor Ntrk2 and the neural stem cell marker Nes (Fig. 2B, C and Suppl. Fig. 2D-2F). Interestingly, Nes (a neural progenitor marker) and Il6st were co-expressed in tanycytes, which are currently held as the main hypothalamic neural stem cells [48]. Il6st mRNA was also detected in vascular leptomeningeal cells (a08. VLMCs), endothelial cells (a03), some neurons (a13, a16), and the pars tuberalis (a19) (Fig. 2D and Suppl. Fig. 2G). Il6ra mRNA expression pattern, on the other hand, was rather restricted to microglia (a07), ependymocytes (a09) and endothelial cells (a03) (Fig. 2D and Suppl. Fig. 2H) and so was Il6ra and Il6st coexpression (Suppl. Fig. 2I). The top five marker genes of each main cell population are shown on Suppl. Fig. 3.

\section{Hypothalamic IL6 is increased in mice genetically protected from diet-induced obesity}

In outbred mice, body mass gain in response to HFD occurs according to a normal distribution [49]. We have previously shown that whenever outbred mice are fed on HFD, there is a direct correlation between caloric intake during the first $24 \mathrm{~h}$ following HFD introduction and body mass gain overtime [49]. Thus, mice presenting 

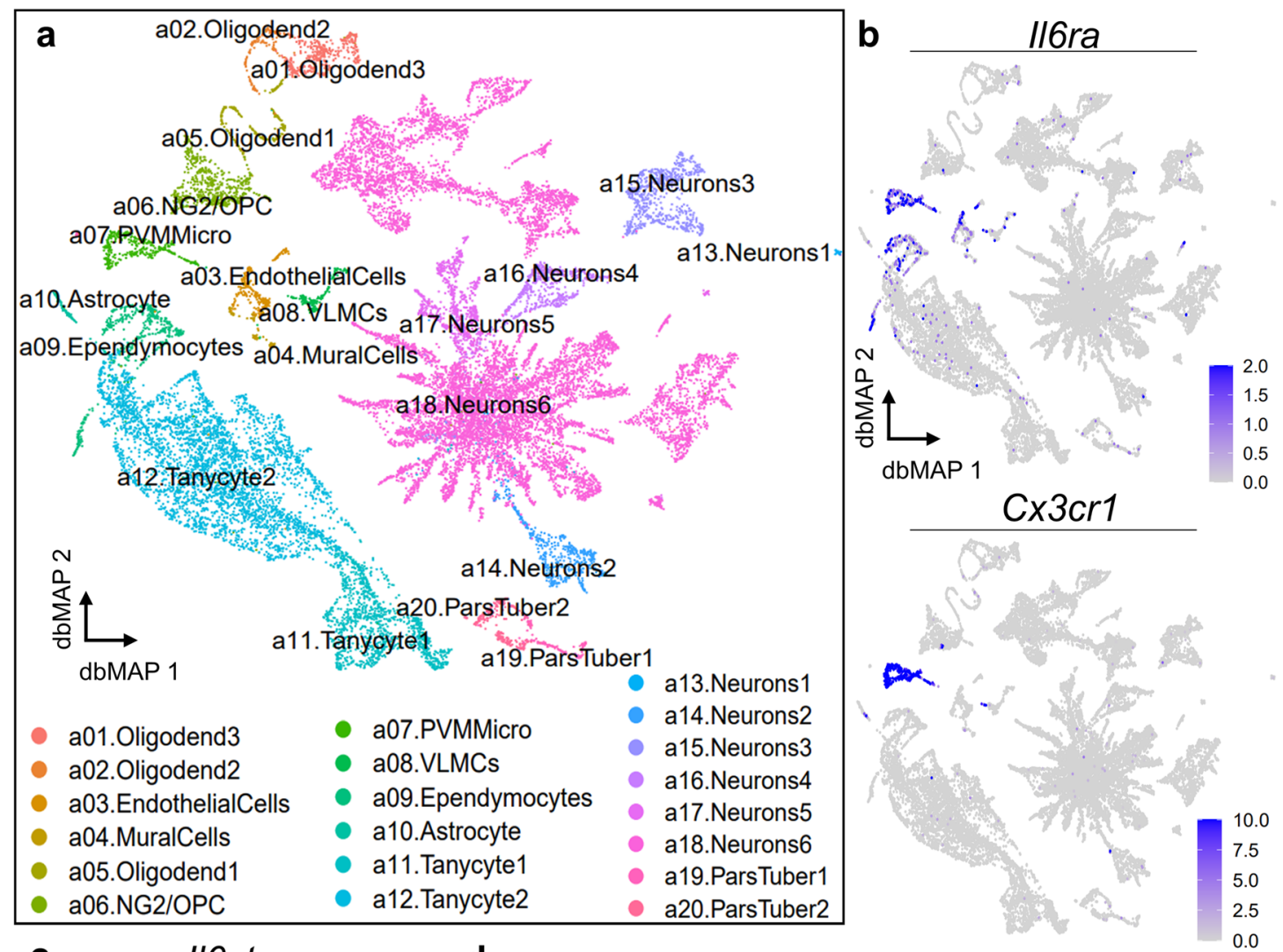

C
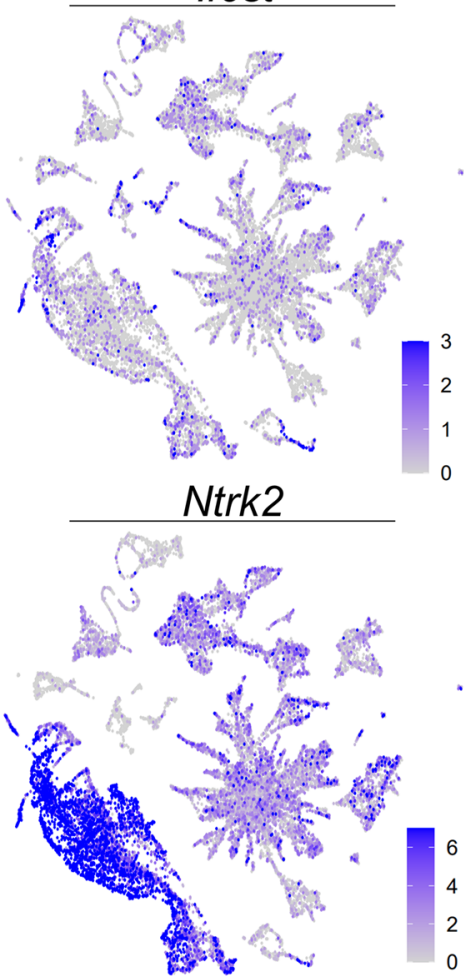

d a01. Oligodend 3 a02. Oligodend2 a03. EndothelialCells a04. MuralCells a05. Oligodend 1 a06. NG2/OPC a07. PVMMicro a08. VLMCs a09. Ependymocytes a10. Astrocytes a11. Tanycyte1 a12. Tanycyte2 a13. Neurons 1 a14. Neurons2 a15. Neurons3 a16. Neurons4 a17. Neurons 5 a18. Neurons6 a19. ParsTuber 1 a20. ParsTuber2

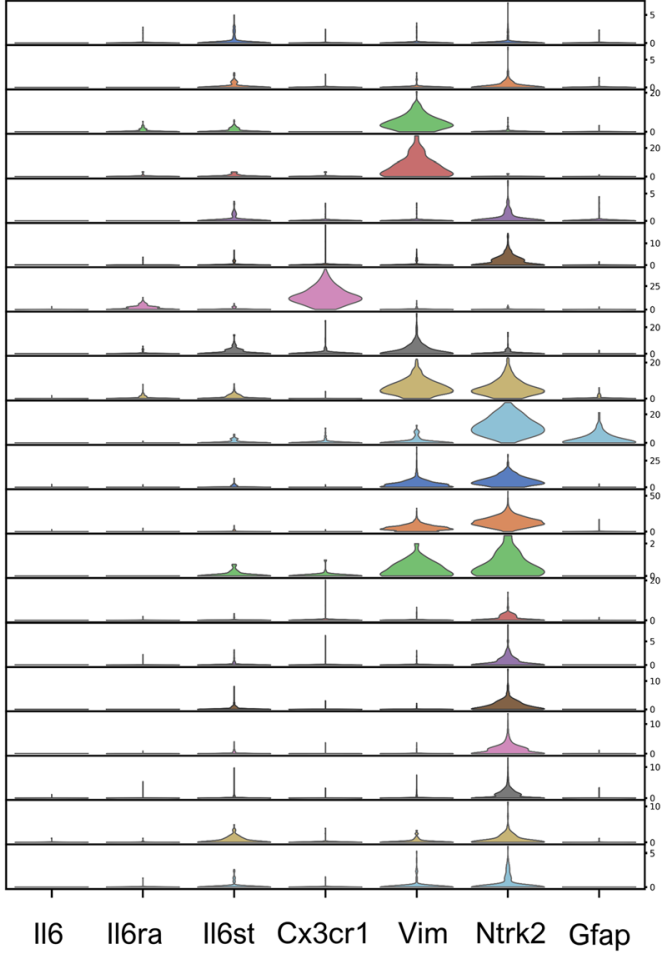

Fig. 2 (See legend on next page.) 
(See figure on previous page.)

Fig. 2 Analysis of single-cell RNA sequencing data reveal the expression pattern of IL6-receptor encoding genes in the arcuate nucleus of the hypothalamus. A Diffusion-based manifold approximation and projection (dbMAP) embedding of 20,921 single-cell transcriptomes of the arcuate nucleus of the hypothalamus, colored by their annotated cluster of origin. In this embedding, similar cells are mapped tightly, whereas dissimilar cells are mapped apart from each other, rendering clusters of cell types. Cells were annotated by their main cell type as defined in the original study. B (top) II6ra mRNA expression, key-colored by expression intensity; Il6ra is found mainly in perivascular macrophages/microglia and ependymocytes and also in astrocytes and endothelial cells. B (bottom) Cx3cr1 (a canonical microglial marker) mRNA expression, key-colored by expression intensity. C (top) I/6st mRNA expression, key-colored by expression intensity; I/6st is broadly expressed in the arcuate with some overlapping with the expression pattern of Ntrk2 (bottom), which encodes a neurotrophic receptor. D Violin plot of the mRNA expressions of $1 / 6$, $\|6 r a\| 6 s t,, C \times 3 c r 1, V i m, N t r k 2$, and Gfap in the arcuate hypothalamus, per main cell types. Oligodend, oligodendrocyte; NG2/OPC, oligodendrocyte progenitor cells; PVMMicro, perivascular macrophages/microglia; VLMCs, vascular and leptomeningeal cells; ParsTuber, pars tuberalis

highest caloric intake are prone to obesity, whereas mice presenting lowest caloric intake are protected from obesity. Here, we asked if diet-induced obesity predisposition or protection is accompanied by differences in hypothalamic IL6 levels (described in "In vivo protocol \#2"). Therefore, mice were submitted to the protocol depicted in Fig, 3A and the hypothalami were extracted $24 \mathrm{~h}$ after diet introduction. As shown in Fig, 3B, IL6 expression was increased in the hypothalamus of obesity-resistant mice.

\section{Palmitate induces a rapid increase in hypothalamic IL6 expression}

Palmitate is the predominant fatty acid in human diet and also in rodent HFD. It has been shown to cross the bloodbrain barrier [50] and it is increased in the cerebrospinal fluid of obese humans [51]. Here, we asked if a direct injection of palmitate in the hypothalamus could increase the expression of IL6. For that, mice were acutely treated with a single intracerebroventricular (icv) dose of palmitate and the hypothalami were extracted for analysis (Fig. 3C) (described in "In vivo protocol \#3"). As shown in Fig, 3D, there was a rapid increase in hypothalamic IL6 transcripts $8 \mathrm{~h}$ after treatment. Palmitate also promoted a trend to increase the transcripts expression of TNF (Fig. 3E) and significantly increased the transcripts expression of IL1 $\beta$ in the hypothalamus (Fig. 3F).

\section{IL6 do not interfere in hypothalamic cell proliferation nor cell survival}

Next, we evaluated the capacity of exogenous IL6 to induce hypothalamic cell proliferation and survival. For that purpose, mice were submitted to two distinct protocols aimed at evaluating cell proliferation (Fig. 4A-C) and cell survival (Fig. 4D-F). At the end of the respective experimental periods, the brains were removed and used to determine the number of BrdU-positive cells during the 7- or 28-day time-windows (described in "In vivo protocol \#4"). As depicted in the representative images of the hypothalamus (Fig. 4B, E) and in the graphical representation of cell counts (Fig. 4C, F), there were no significant differences between the groups.

\section{IL6 induces hypothalamic neurogenesis, as well as expression of neurogenesis-related transcripts in the hypothalamus}

Next, we evaluated the effect of IL6 to induce the expression of neurogenesis-related genes in the hypothalamus. For that, mice were treated with IL6 according to the protocol as depicted in Fig. 5A and the hypothalami were extracted for determination of gene expression (described in "In vivo protocol \#5"). As shown in Fig. 5B and C, IL6 promoted increased expressions of Sox6 and Sox 2 transcripts that encode transcription factors involved in neurogenesis, specifically in neural stem cells, during the proliferative state [52-54]. In addition, when looking into putative differences in the neurogenic response to IL6 comparing obesity-prone $(\mathrm{H})$ and obesity-resistant (L) mice (described in "In vivo protocol \#2"), we found that ip IL6 promoted a significantly larger expression of Sox6 transcripts (Fig. 5D) and a trend for increase of doublecortin transcripts (Fig. 5E) in obesity-resistant mice. Next, employing the same protocol as depicted in Fig. 4D (described in "In vivo protocol \#4", survival), we determined the number of BrdU-positive cells colocalizing with NeuNpositive cells. As shown in Fig. 5F and G, IL6 promoted an increased neuronal differentiation after 14 days, revealing its capacity to drive proliferative cells into a neuronal fate $(p=$ 0.008 , unpaired $T$-test, two-tailed). The total number of cells determined in this experiment are depicted in Suppl. Fig. 4.

\section{IL6 knockout mice are heavier and present a reduced expression of POMC in the hypothalamus}

Next, we evaluated body mass and hypothalamic gene expression in IL6 knockout (KO) mice (described in "In vivo protocol \#6"). First, we tested if KOs were indeed completely depleted of circulating IL6, and if exogenous IL6 could promote a detectable increase of its blood levels. As shown in Fig. 6A, IL6 KO mice presented no detectable blood IL6 and the injection of $1 \mathrm{ng}$ of IL6, $4 \mathrm{~h}$ prior to blood collection, resulted in the detection of blood IL6 in two out of four mice. At age 8 weeks, IL6 KO were heavier than controls (Fig. 6B), and at age 7 days, there were no differences in the expression of hypothalamic transcripts encoding for peptides related to energy homeostasis (Fig. 6C). However, at age 8 weeks, the expression of POMC was lower in IL6 KO as 

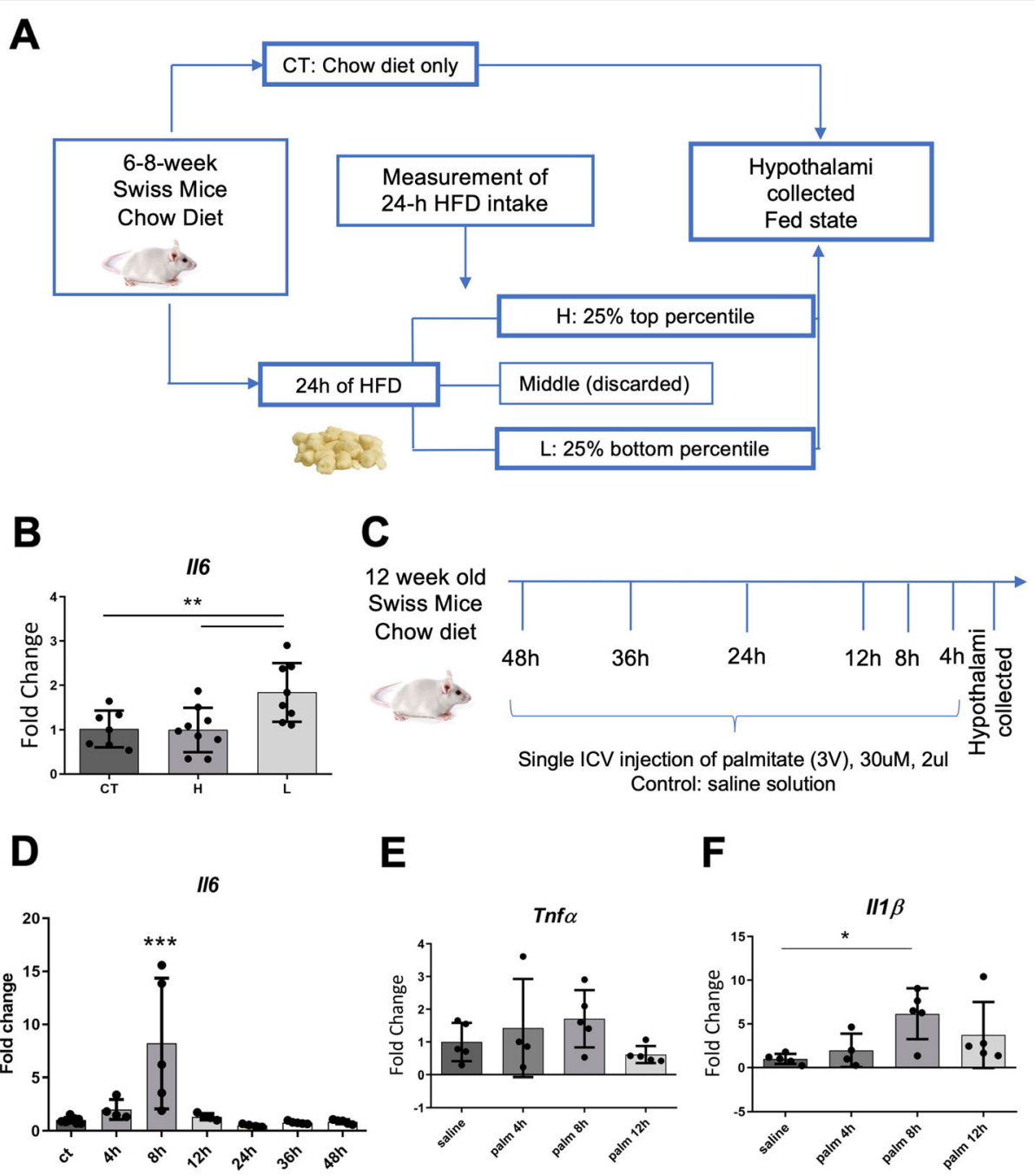

Fig. 3 Hypothalamic transcript expression of IL6. In order to identify obese-prone (H) and obese-resistant (L) mice, we performed the procedure as depicted in A. The expression of hypothalamic IL6 was determined using real-time PCR (B). Palmitate was injected in a single intracerebroventricular (ICV) dose and hypothalamus was collected (C) for determinations of IL6 (D), TNFa (E), and IL1 $\beta$ (F) transcripts. B, $n=7-8$ mice/group; D-F, $n=5$ mice/group; ${ }^{*} p<0.05,{ }^{* *} p<0.01$, ${ }^{* * *} p<0.001$. In bar graphs, results are presented as mean \pm standard deviation

compared to control (Fig. 6D). Regarding transcripts related to neurogenesis, at age 7 days, IL6 KO presented lower levels of hypothalamic Gfap (Fig. 6E), whereas at age 8 weeks there were no differences between IL6 KO and control (Fig. 6F).

\section{IL6 increases markers of neurogenesis in hypothalamic neuroprogenitor cells}

Next, we employed neuroprogenitor cells (NPCs) obtained from IL6 KO mice. The cells were expanded using a method to generate neurospheres. Thereafter, NPCs were employed to determine the direct effect of IL6 to promote differentiation towards a neuronal fate. The expressions of Pomc and Npy transcripts were increased in the hypothalamic NPCs obtained from IL6 KO mice (Fig. 7A). When IL6 was added to culture media, there was an increased expression (mRNA and protein) of doublecortin and reduced mRNA expressions of Pomc and Npy (Fig. 7B-D). In addition, IL6 promoted a trend to increase the number of doublecortin positive cells (Fig. 7C, D) and a significant increase in the number of MAP2 positive cells (Fig. 7E, F). In NPCs differentiated for longer time (10-14 days), IL6 promoted increased expressions of doublecortin (Fig. 7G, H) and NeuroD1 transcripts (Fig. 7I, J), a reduction of Pomc (Fig. 7K), and no changes in Npy (Fig. 7L) and Gfap transcripts (Fig. 7M).

\section{Discussion}

Adult neurogenesis warrants neuronal renewal throughout life [25]. It relies on the existence of neural stem/progenitor cells (NSPCs) that reside in a few brain niches and respond 


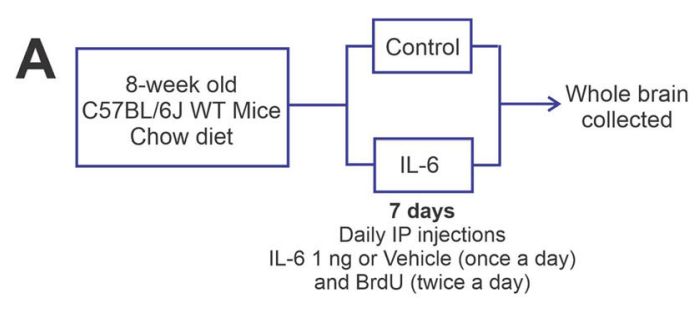

B
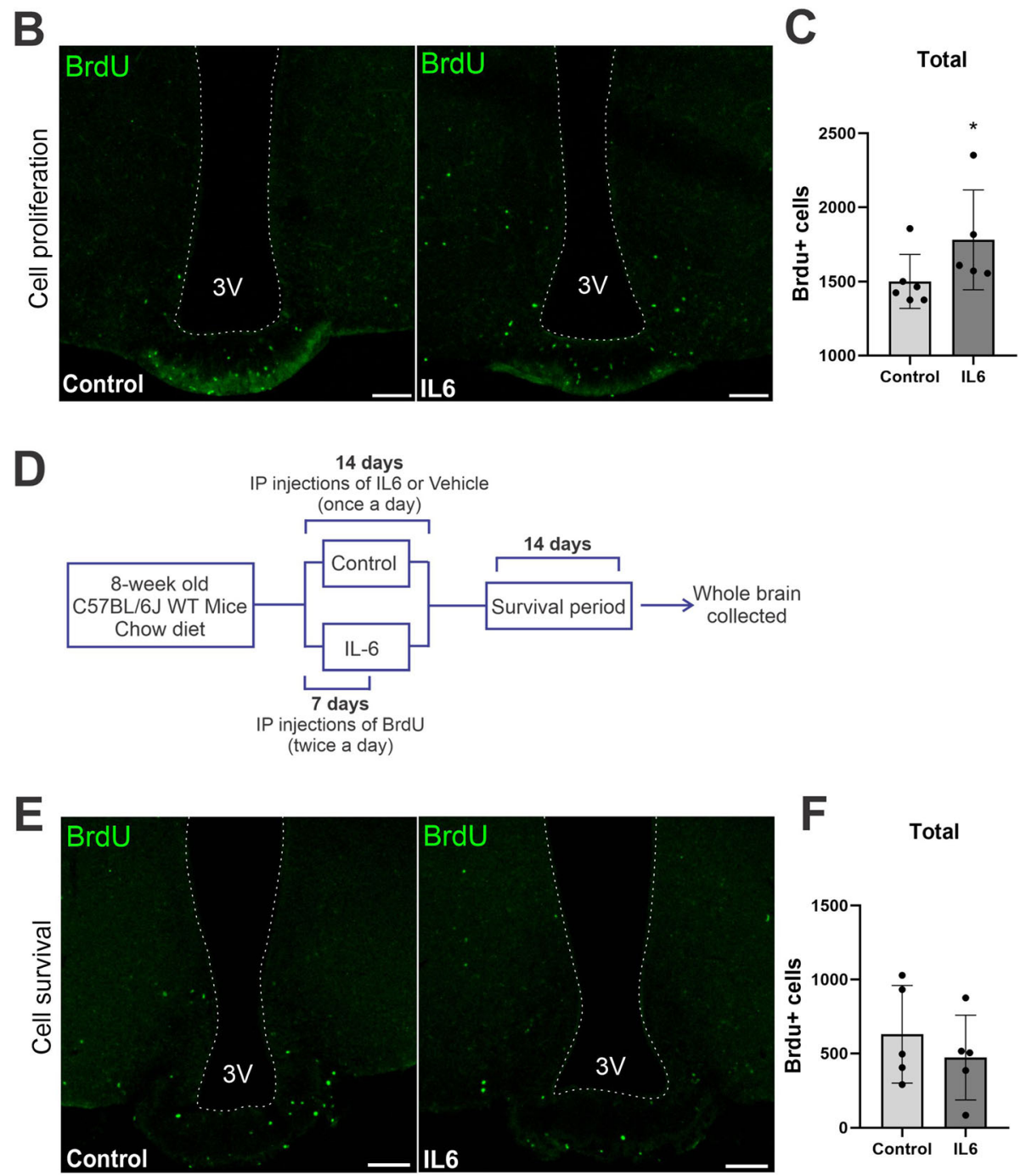

Fig. 4 IL6 effect on hypothalamic cell proliferation and survival. Mice were treated with IL6 and BrdU according to the protocols as depicted in A and D. The mediobasal hypothalamus was prepared for analysis using immunofluorescence and confocal microscopy; cell counting was performed using 20X and 40X magnifications. Representative images are presented in $\mathbf{B}$ (proliferation assay) and $\mathbf{E}$ (survival assay). Total BrdU countings are presented in $\mathbf{C}$ (proliferation assay) and $\mathbf{F}$ (survival assay). In both assays, $n=6$ mice/group. In bar graphs, results are presented as mean \pm standard deviation

to distinct endogenous and exogenous stimuli, differentiating to integrate specific networks [55-59]. The SVZ and the SGZ are the most important neurogenic niches producing new neurons involved in a multitude of functions such as memory, cognition, and olfaction [60-62]. A smaller neurogenic niche exists in the hypothalamus and is responsible for the renewal of neurons involved in whole body energy homeostasis $[27,28]$.
Neurons of the mediobasal hypothalamus (MBH) control food intake and energy expenditure in response to signals delivered by hormones, neural inputs, and nutrients [44, 63-67]. In obesity and aging, hypothalamic inflammation leads to neuronal loss, which affects the balance between neuronal subpopulations exerting anabolic and catabolic functions [68-71]. Certain stimuli can promote a neurogenic response that results in the 

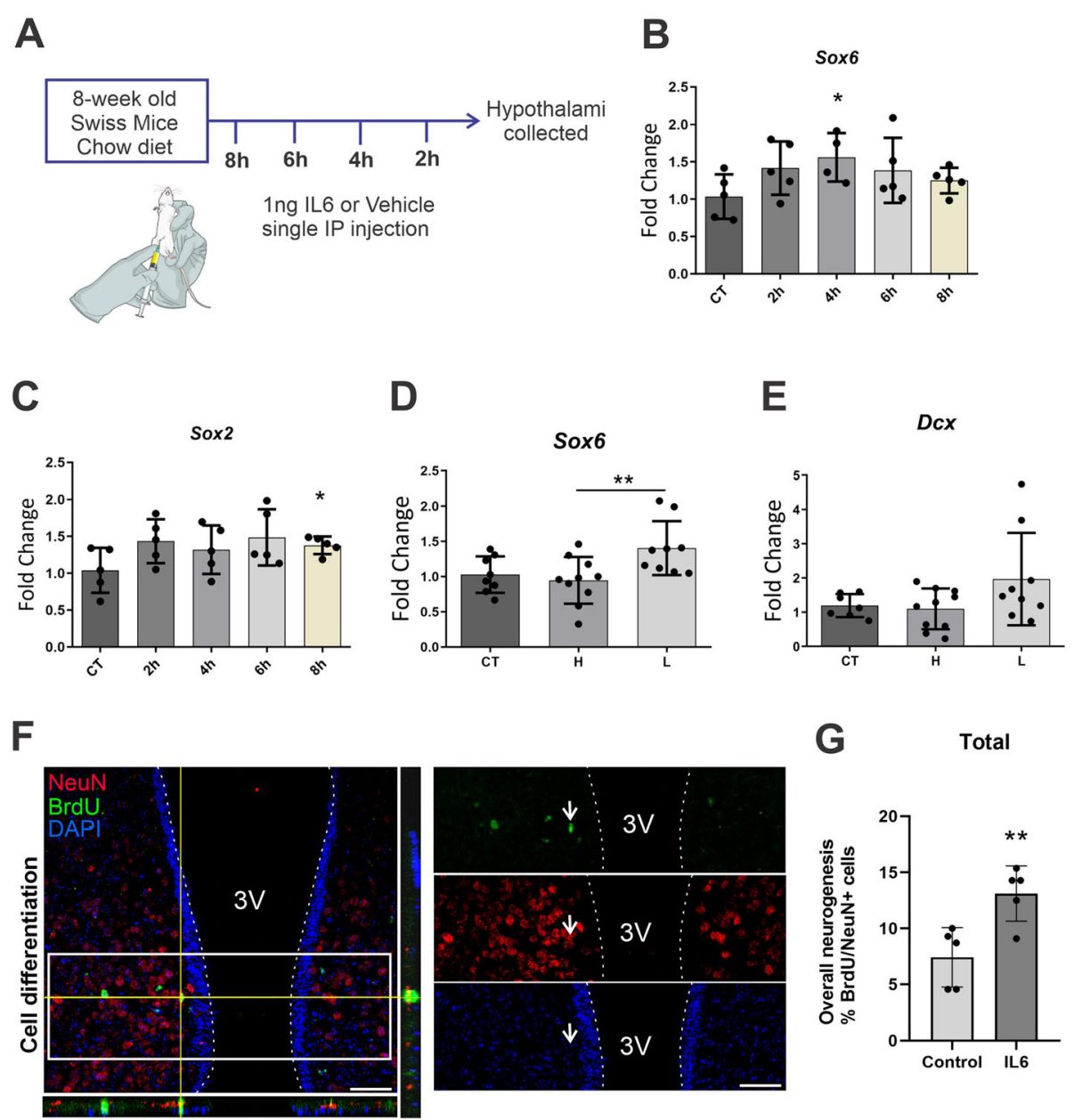

Fig. 5 IL6 induces neurogenesis in the hypothalamus. Mice were treated with a single intraperitoneal dose of IL6, according to the protocol as depicted in $\mathbf{A}$. The hypothalamic expressions of Sox6 (B) and Sox2 $(\mathbf{C})$ were determined using real-time PCR. The transcript expressions of Sox6 (D) and doublecortin (E) were determined in the hypothalami collected from obese-prone (H) and obese-resistant (L) mice and treated with a single dose of IL6. F Mice were treated with IL6 and BrdU according to the protocols as depicted in Fig. 4D. The mediobasal hypothalamus was prepared for analysis using immunofluorescence and confocal microscopy; cell counting was performed using 20x and 40x magnifications. Total BrdU/NeuN counting is depicted in $\mathbf{G}$ (neurogenesis assay). B, C $n=5$ mice/group; $\mathbf{D}, \mathbf{E} n=8-10$ mice/group; $\mathbf{F}, \mathbf{G}, n=5$ mice/group. ${ }^{*} p<0.05$, ${ }^{* *} p<0.01$. In bar graphs, results are presented as mean \pm standard deviation

generation of neurons that could reestablish homeostasis $[27,28,31]$. Thus, it is believed that pharmacological and nutritional approaches leading to the generation of new hypothalamic neurons that counterbalance the effects of obesity and ageing could be useful in therapeutics $[63,72-74]$.

Here, we tested the hypothesis that IL6 could induce hypothalamic neurogenesis. The hypothesis was based in two premises: (i) IL6 produced in response to exercise improves memory and cognition, at least in part, due to its neurogenic roles in the hippocampus $[19,23]$ and (ii) IL6 produced in response to exercise reduce obesityassociated hypothalamic inflammation restoring the control of food intake and energy expenditure [21].

First, we showed that exogenous IL6 can reduce body mass gain in mice fed HFD but not in mice fed chow.
These results are in concert with the fact that IL6 KO mice develop late-onset obesity and the replacement of exogenous IL6 corrects the phenotype [75]. Most of the effects of IL6 to reduce body mass depends on its action in the hypothalamus [75]. It is long known that both IL6 and its receptor are expressed in the hypothalamus [76]; however, with the recent advance in single-cell transcriptome technology, details regarding the expression of distinct transcripts can be traced to subpopulation levels [77]. To explore the expression profiles of $I l 6$ and Il6ra in the hypothalamus cellular landscape, we analyzed 20,921 public single-cell transcriptomes [46] with the dbMAP dimensionality reduction method [45]. This is the first single-cell analysis of IL6 and IL6 receptors in the hypothalamus, providing advance by showing that Il6 is lowly expressed and restricted to microglia and 


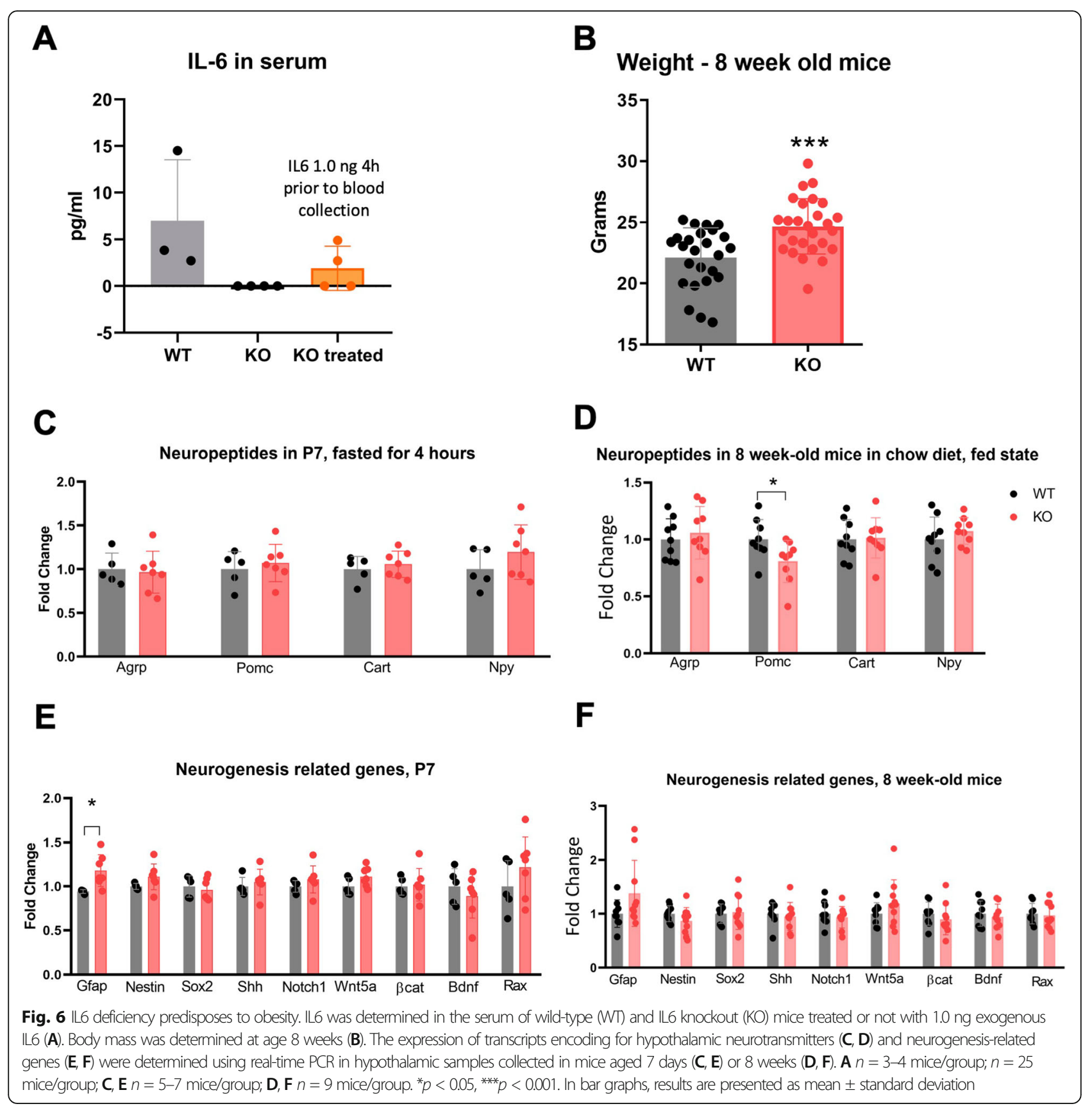

tanycytes, whereas its canonical receptor Il6ra is consistently expressed in ependymocytes, astrocytes, endothelial cells, and particularly in the microglia. On the other hand, Il6st, which is needed for Il6ra signaling and might be directed activated by IL6 trans-signaling [78], is broadly expressed across almost all cell types, and particularly in neurons and tanycytes, although Il6st and Il6ra mRNA co-expression was detectable only in microglia and ependymocytes, suggesting classical IL6 signaling through IL6RA is restricted to these cell types in the arcuate hypothalamus.
In humans, exposure to environmental factors that predispose to obesity, results in variable body mass gain, which occurs according to a normal distribution [79]. This reflects the genetic nature of obesity-prone and obesity-resistant phenotypes [80]. Similar pattern occurs whenever outbred rodents are fed on HFD $[49,81]$. Previously, we showed that rapid regulation of hypothalamic POMC following the introduction of HFD is an important factor determining predisposition to obesity $[49,70]$. Here, we showed that obesity-resistant mice express larger amounts of IL6 than obesity-prone mice. These data 


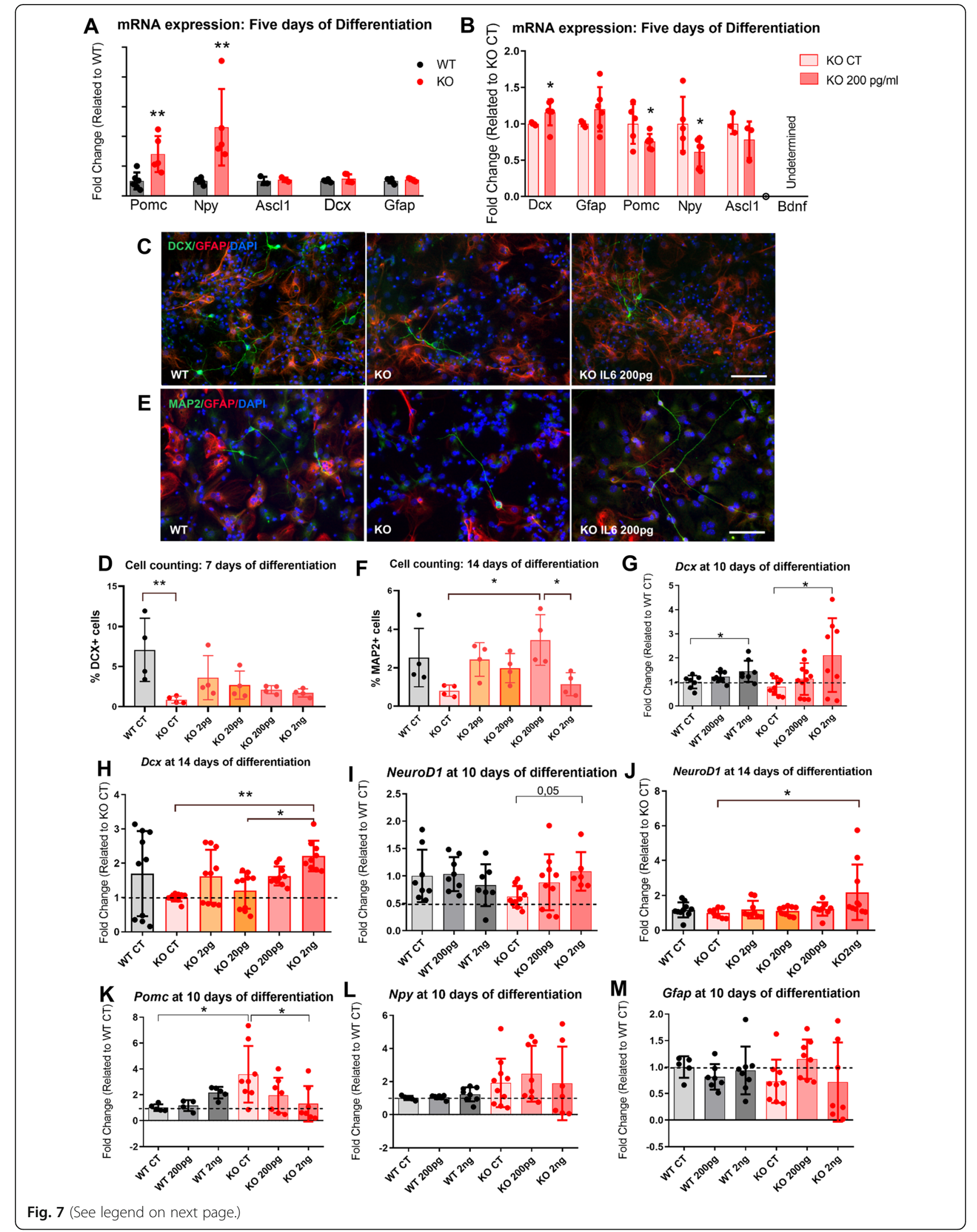

B $\mathcal{G}$ mRNA expression: Five days of Differentiation 
(See figure on previous page.)

Fig. 7 ॥L6 induce neurogenic factors expression in hypothalamic neuroprogenitor cells (NPCs). Transcripts were determined using real-time PCR in the NPCs of WT and IL6 KO mice after a 5-day differentiation period: first, WT and IL6 KO hypothalamic cells were analyzed in basal conditions (A), and then, IL6 KO NPCS were treated with exogenous IL6 in doses depicted (B). Representative immunocytochemistry images of 7-day differentiated cells (green, DCX; red, GFAP; blue, DAPI) (C) and DCX-positive cell counting (D), and representative immunocytochemistry images of 14-day differentiated cells (green, MAP2; red, GFAP; blue, DAPI) (E) and MAP2-positive cell counting (F). After 10- (G, I, K-M) or 14-day ( $\mathbf{H}$ and $\mathbf{J})$ differentiation period, transcripts were determined using real-time PCR in the NPCs of WT and IL6 KO mice treated with exogenous IL6 in doses depicted in the panels (G-M). A, B $n=12$ (3-4 well/group, 2 independent experiments); C-F $n=24$ ( 4 well/group, 2 independent experiments); G-M $n=48$ (6-9 well/group, 3 independent experiments). ${ }^{*} p<0.05,{ }^{* *} p<0.01$. In bar graphs, results are presented as mean \pm standard deviation

provide additional support for the anti-obesity actions of IL6 [21, 75] and suggests that enhanced capacity to produce IL6 in the hypothalamus could be a genetically determined mechanism that protects against excessive body mass gain. This is further supported by human studies that show both obesity-protection [3] and obesity predisposition [82] associated with different polymorphisms of the IL6 gene.

Next, using a living-mouse model, we showed that ip IL6 was capable of increasing the number of newly generated neurons in the arcuate nucleus of the hypothalamus. This was accompanied by the increased expression of neurogenic-related transcripts Sox 2 and Sox6. Moreover, we showed that the neurogenic response was more evident in obesity-resistant mice. This is the first evidence for a pro-neurogenic action of IL6 in the hypothalamus. There are few studies that have evaluated the potential implication of IL6 in adult neurogenesis and all of them were focused on the hippocampus. Some studies showed that chronically, IL6 could impair neurogenesis [83, 84]; however, two studies have shown that in the context of exercise, IL6 could promote neurogenesis impacting positively in memory and cognition $[19,23]$, whereas another study has shown an increase in hippocampal IL6 occurring in response to a neurogenic stimulus provided by marrow-derived mesenchymal stem cells [85].

Further insight into the roles of IL6 in hypothalamic neurogenesis was obtained determining the expression of neurogenic-related genes and neurotransmitters in IL6 KO mice. First, we reproduced results of previous studies showing that IL6 KO mice are obese-prone [75]. Next, we showed that in mice aged 7 days there was increased expression of hypothalamic Gfap, whereas in mice aged 8 weeks, there was a reduction of POMC. This could indicate an abnormal neurogenic process, since Gfap is a marker of both astrocytes and tanycytes, cells that are involved in hypothalamic neurogenesis [86, 87]. The reduction of POMC could result from the abnormal neurogenic process and contribute to the obese-prone phenotype of IL6-deficient mice [31, 88, 89].

In the last part of the study, we evaluated NPCs produced from IL6 KO mice hypothalami. Both proliferation rate and expression of POMC and NPY were increased at the baseline. Upon treatment with IL6,
NPCs that differentiated for five days presented increased expression of doublecortin and decreased expression of POMC and NPY. Doublecortin is a microtubule-associated protein that expresses early during the development of neurons [90]; we reasoned that stimulation with IL6 could be inducing an upsurge of neurogenesis and only undifferentiated neurons could be detected at this time. Therefore, we increased differentiation time for 10 and 14 days; NPY expression was normalized, however, increased doublecortin persisted and was accompanied by similar changes in the expression of NeuroD1, another important factor associated with adult neurogenesis [91]. Nevertheless, the IL6-induced reduction of POMC persisted suggesting that in the IL6 deficient environment the stimulus with exogenous IL6 could generate an abnormal pattern of either survival or generation of specific neuronal populations.

Because of the functional nature of many neurons in the $\mathrm{MBH}$, which are involved in the control of caloric intake and energy expenditure, it was expected that neurogenic stimuli affecting neurons of this region could impact on whole body energy homeostasis. In fact, we showed that exogenous IL6 reduces body mass, whereas IL6 deficiency results in obesity predisposition. Moreover, in IL6 KO mice, the hypothalamic transcript levels of POMC are reduced. At least in part, these effects could be attributed to the hypothalamic neurogenic actions of IL6. We acknowledge that studding the whole $\mathrm{MBH}$ and not specific cell subpopulations is a limitation of this study that could be further explored in the future.

\section{Conclusions}

In this study, we provide the evidence for a role of IL6 in the regulation of hypothalamic neurogenesis. Both, in living mice and NPCs, IL6 stimulated cell proliferation and induced the expression of markers of immature neurons; however, in IL6 deficiency, exogenous IL6 administration seem to modify the pattern of differentiation of neurons. Further studies should define the mechanism linking IL6-induced neurogenesis with neuronal fate determination.

\section{Abbreviations}

ASCL1: Achaete-scute homolog 1; BDNF: Brain-derived neurotrophic factor; BrdU: Bromodeoxyuridine; CEUA: Ethics committee on animal use;

Ct: Control; Cx3Cr1: C-x3-c motif chemokine receptor 1; DCX: Doublecortin; 
DMEM: Dulbecco's modified eagle medium; DNA: Deoxyribonucleic acid; EGF: Endotelial growth factor; FGF: Fibroblast growth factor; GAPD H: Glyceraldehyde 3-phosphate dehydrogenase; GFAP: Glial fibrillary acidic protein; HFD: High-fat diet; ICV: Intracerebroventricular; IL-1 13: Interleukin-1B; IL-6: Interleukin-6; IL6ra: Interleukin-6 receptor subunit alpha; IL6st: Interleukin-6 cytokine family signal transducer; IP: Intraperitoneal; KO: Knockout; L: Low intake of high-fat diet; $\mathrm{H}$ : High intake of high-fat diet; HCl: Hydrochloric acid; MAP 2: Microtubule-associated protein 2; MBH: Mediobasal hypothalamus; mRNA: Messenger ribonucleic acid; NeuroD1: Neuronal differentiation; NeuN: Nuclear neuronal antigen; NPC: Neural progenitor cells; NSC: Neural stem cells; Ntrk2: Neurotrophic receptor tyrosine kinase 2; NPY: Neuropeptide Y; PBS: Phosphate saline buffer; PCR: Polymerase chain reaction; POMC: Proopiomelanocortin; RNA: Ribonucleic acid; SGZ: Subgranular zone; SOX: Sex determining region Y box; SVZ: Subventricular zone; TNF-a: Tumor necrosis factor a; WT: Wildtype

\section{Supplementary Information}

The online version contains supplementary material available at https://doi. org/10.1186/s12974-021-02242-8

Additional file 1: Supplementary Figure 1. Effect of exogenous IL6 on caloric intake and body mass. Wild-type mice were fed on chow or high-fat diet (HFD) and treated intraperitoneally (IP) with exogenous IL6 as depicted in Figure 1A. Body mass (A) and caloric intake (B) were determined in mice fed chow and HFD. In all experiments, $n=5$ mice/group. Two-way ANOVA with repeated measures and Bonferroni post-test was applied for the statistics of all data. ${ }^{*} \mathrm{p}<0.05$, IL6 HFD vs. saline HFD (day 7 and day 14). ${ }^{*} p<0.05$, saline HFD vs. saline chow (day 14). ${ }^{*} p<0.05$, saline HFD vs. IL6 chow (day 14). Supplementary Figure 2. Bayesian analysis of single-cell RNA sequencing data and key genes coexpression patterns. A-F. dbMAP embeddings of the arcuate nucleus and median eminence scRNAseq data, colored by raw mRNA expression levels (left) or corresponding Bayesian probabilistic-denoised counts levels (right). Bayesian analysis was performed with BASiCS (Bayesian Analysis for Single-Cell Sequencing). G. dbMAP embedding key-colored by Nes (red) and II6st (green) mRNA co-expression levels. H. dbMAP embedding key-colored by Cx3cr1 (red) and Il6ra (green) mRNA co-expression levels. I. dbMAP embedding key-colored by $\| 6 r a$ (red) and $\| 6 s t$ (green) mRNA co-expression levels. Supplementary Figure 3. Heatmap of top five marker genes for the arcuate nucleus and median eminence main cell types. Heatmap showing mRNA expression of top five marker genes from the main cell types of the arcuate nucleus and median eminence. Marker genes were found with a Wilcoxon rank-sum test and then scaled. Z-scores are then used for coloring. Supplementary Figure 4. IL6 effect on hypothalamic cell proliferation and survival. Mice were treated with IL6 and BrdU according to the protocols as depicted in Fig. 4A and 4D. The mediobasal hypothalamus was prepared for analysis using immunofluorescence and confocal microscopy; cell counting was performed using 20X and 40X magnifications. Abercrombie corrected total BrdU countings are presented in A (proliferation assay) and $B$ (survival assay). In both assays, $n=6$ mice/ group). In bar-graphs results are presented as mean \pm standard deviation. Supplementary Figure 5. Total number of cells determined in the experiment depicted in Figure 5G. Mice were treated with IL6 and BrdU according to the protocols as depicted in Figure 4D. The mediobasal hypothalamus was prepared for analysis using immunofluorescence and confocal microscopy; cell counting was performed using 20X and 40X magnifications. $\mathrm{N}=5$ mice/group. Supplementary Table 1. Detailed information of primers used in the study. All primers were purchased from Thermo Fischer Scientific. Supplementary Table 2. Raw data for statistical analysis

\section{Acknowledgements}

Vanessa Bobbo received financial support from the São Paulo Research Foundation. The authors thank Erika Roman, Marcio Cruz, and Gerson Ferraz for laboratory management. The study was supported by grants from the São Paulo Research Foundation (2013/07607-8) and Conselho Nacional de Pesquisa e Desenvolvimento Científico.

\section{Authors' contributions}

Conceptualization, VCB, JM, LAV, and EPA. Methodology, VCB, DFE, and JM. In vivo experiments, VCB, DFE, CPJ, NFM, RH-T, TPP, and JM. Ex vivo experiments, VCB and DFE. Single-cell RNA data analysis, DS-O. Resources, LAV and EPA. Analyses, VCB, JM, LAV, and EPA. Writing, VCB, DFE, LAV, and EPA. The authors read and approved the final manuscript.

\section{Funding}

The study was supported by grants from the São Paulo Research Foundation (2013/07607-8) and Conselho Nacional de Pesquisa e Desenvolvimento Científico.

Availability of data and materials

Data and materials are available upon request.

\section{Declarations}

Ethics approval and consent to participate

All experiments were conducted according to the "Guide for the Care and Use of Laboratory Animals of the Institute of Laboratory Animal Resources, US National Academy of Sciences" and were approved by the Ethics Committee (CEUA IB/UNICAMP \#3987-1, \#4361-1, \#4775-1). All animal experiments were performed in a biosafe facility and were approved by the University of Campinas Biosafety Committee.

\section{Consent for publication}

All authors have provided informed consent for publication of this study.

\section{Competing interests}

The authors declare that they have no competing interests.

Received: 22 April 2021 Accepted: 18 August 2021

Published online: 31 August 2021

\section{References}

1. Kang S, Tanaka T, Narazaki M, Kishimoto T. Targeting interleukin-6 signaling in clinic. Immunity. 2019;50(4):1007-23. https://doi.org/10.1016/j.immuni.201 9.03.026.

2. Mauer J, Denson JL, Bruning JC. Versatile functions for IL-6 in metabolism and cancer. Trends Immunol. 2015;36(2):92-101. https://doi.org/10.1016/j.it.2 014.12.008.

3. Anderson P. Post-transcriptional regulons coordinate the initiation and resolution of inflammation. Nat Rev Immunol. 2010;10(1):24-35. https://doi. org/10.1038/nri2685

4. Tanaka T, Narazaki M, Kishimoto T. IL-6 in inflammation, immunity, and disease. Cold Spring Harb Perspect Biol. 2014;6(10):a016295. https://doi.org/1 $0.1101 /$ cshperspect.a016295.

5. Hop HT, Huy TXN, Reyes AWB, Arayan LT, Vu SH, Min W, et al. Interleukin 6 promotes Brucella abortus clearance by controlling bactericidal activity of macrophages and CD8(+) T cell differentiation. Infect Immun. 2019;87(11). https://doi.org/10.1128/IAl.00431-19.

6. Matuschak GM, Munoz C, Epperly NA, Britton RS, Walsh D, Schilly DR, et al. TNF-alpha and IL-6 expression in perfused rat liver after intraportal candidemia vs. E. coli or S. aureus bacteremia. Am J Physiol. 1994;267(2 Pt 2): R446-54. https://doi.org/10.1152/ajpregu.1994.267.2.R446.

7. Onogawa T. Local delivery of soluble interleukin-6 receptors to improve the outcome of alpha-toxin producing Staphylococcus aureus infection in mice Immunobiology. 2005;209(9):651-60. https://doi.org/10.1016/j.imbio.2004.09.006.

8. Alonzi T, Fattori E, Lazzaro D, Costa P, Probert L, Kollias G, et al. Interleukin 6 is required for the development of collagen-induced arthritis. J Exp Med. 1998;187(4):461-8. https://doi.org/10.1084/jem.187.4.461.

9. Georganas C, Liu H, Perlman H, Hoffmann A, Thimmapaya B, Pope RM. Regulation of IL-6 and IL-8 expression in rheumatoid arthritis synovial fibroblasts: the dominant role for NF-kappa B but not C/EBP beta or C-Jun. J Immunol. 2000;165(12):7199-206. https:/doi.org/10.4049/jimmunol.165.12.7199.

10. Klover PJ, Clementi AH, Mooney RA. Interleukin-6 depletion selectively improves hepatic insulin action in obesity. Endocrinology. 2005;146(8):341727. https://doi.org/10.1210/en.2004-1468.

11. Roderburg C, Trautwein C. Obesity and liver cancer: a key role for interleukin-6 and signal transducer and activator of transcription 3? Hepatology. 2010;51(5):1850-2. https://doi.org/10.1002/hep.23693. 
12. Tian G, Mi J, Wei X, Zhao D, Qiao L, Yang C, et al. Circulating interleukin-6 and cancer: a meta-analysis using Mendelian randomization. Sci Rep. 2015 5(1):11394. https://doi.org/10.1038/srep11394.

13. Jonsdottir $\mathrm{H}$, Schjerling P, Ostrowski K, Asp S, Richter EA, Pedersen BK. Muscle contractions induce interleukin- 6 mRNA production in rat skeletal muscles. J Physiol. 2000;528(Pt 1):157-63. https://doi.org/10.1111/j.14697793.2000.00157.x

14. Pedersen BK, Febbraio MA. Muscle as an endocrine organ: focus on musclederived interleukin-6. Physiol Rev. 2008;88(4):1379-406. https://doi.org/10.11 52/physrev.90100.2007.

15. Glund S, Deshmukh A, Long YC, Moller T, Koistinen HA, Caidahl K, et al. Interleukin-6 directly increases glucose metabolism in resting human skeletal muscle. Diabetes. 2007;56(6):1630-7. https:/doi.org/10.2337/db06-1733.

16. Kurauti MA, Costa-Junior JM, Ferreira SM, Santos GJ, Sponton CHG, Carneiro EM, et al. Interleukin-6 increases the expression and activity of insulin-degrading enzyme. Sci Rep. 2017;7(1):46750. https:/doi.org/10.1038/srep46750.

17. Peppler WT, Townsend LK, Meers GM, Panasevich MR, MacPherson REK, Rector RS, et al. Acute administration of IL-6 improves indices of hepatic glucose and insulin homeostasis in lean and obese mice. Am J Physiol Gastrointest Liver Physiol. 2019;316(1):G166-G78. https://doi.org/10.1152/a jpgi.00097.2018.

18. Townsend LK, Medak KD, Peppler WT, Meers GM, Rector RS, LeBlanc PJ, et al. High-saturated-fat diet-induced obesity causes hepatic interleukin-6 resistance via endoplasmic reticulum stress. J Lipid Res. 2019;60(7):1236-49. https://doi.org/10.1194/jlr.M092510.

19. Baier PC, May U, Scheller J, Rose-John S, Schiffelholz T. Impaired hippocampus-dependent and -independent learning in IL-6 deficient mice. Behav Brain Res. 2009;200(1):192-6. https://doi.org/10.1016/j.bbr.2009.01.013.

20. Gomes da Silva S, Simoes PS, Mortara RA, Scorza FA, Cavalheiro EA, da Graca Naffah-Mazzacoratti M, et al. Exercise-induced hippocampal antiinflammatory response in aged rats. J Neuroinflammation. 2013;10:61.

21. Ropelle ER, Flores MB, Cintra DE, Rocha GZ, Pauli JR, Morari J, et al. IL-6 and IL-10 anti-inflammatory activity links exercise to hypothalamic insulin and leptin sensitivity through IKKbeta and ER stress inhibition. PLoS Biol. 2010; 8(8):e1000465. https://doi.org/10.1371/journal.pbio.1000465.

22. Silva VRR, Micheletti TO, Katashima CK, Lenhare L, Morari J, Moura-Assis A, et al. Exercise activates the hypothalamic S1PR1-STAT3 axis through the central action of interleukin 6 in mice. J Cell Physiol. 2018;233(12):9426-36. https://doi.org/10.1002/jcp.26818.

23. Choi SH, Bylykbashi E, Chatila ZK, Lee SW, Pulli B, Clemenson GD, et al Combined adult neurogenesis and BDNF mimic exercise effects on cognition in an Alzheimer's mouse model. Science. 2018;361(6406): eaan8821. https://doi.org/10.1126/science.aan8821.

24. Willis EF, MacDonald KPA, Nguyen QH, Garrido AL, Gillespie ER, Harley SBR, et al. Repopulating microglia promote brain repair in an IL-6-dependent manner. Cell. 2020;180(5):833-46 e16. https:/doi.org/10.1016/j.cell.2020.02.013.

25. Ernst A, Frisen J. Adult neurogenesis in humans - common and unique traits in mammals. PLoS Biol. 2015;13(1):e1002045. https://doi.org/10.1371/ journal.pbio. 1002045 .

26. Ming GL, Song $\mathrm{H}$. Adult neurogenesis in the mammalian brain: significant answers and significant questions. Neuron. 2011;70(4):687-702. https://doi. org/10.1016/j.neuron.2011.05.001.

27. Kokoeva MV, Yin H, Flier JS. Neurogenesis in the hypothalamus of adult mice: potential role in energy balance. Science. 2005;310(5748):679-83. https://doi.org/10.1126/science.1115360.

28. McNay DE, Briancon N, Kokoeva MV, Maratos-Flier E, Flier JS. Remodeling of the arcuate nucleus energy-balance circuit is inhibited in obese mice. J Clin Invest. 2012;122(1):142-52. https://doi.org/10.1172/JCl43134.

29. Bless EP, Reddy T, Acharya KD, Beltz BS, Tetel MJ. Oestradiol and diet modulate energy homeostasis and hypothalamic neurogenesis in the adult female mouse. J Neuroendocrinol. 2014;26(11):805-16. https://doi.org/1 $0.1111 /$ jne.12206.

30. Desai M, Li T, Ross MG. Hypothalamic neurosphere progenitor cells in low birth-weight rat newborns: neurotrophic effects of leptin and insulin. Brain Res. 2011;1378:29-42. https://doi.org/10.1016/j.brainres.2010.12.080.

31. Nascimento LF, Souza GF, Morari J, Barbosa GO, Solon C, Moura RF, et al. n3 fatty acids induce neurogenesis of predominantly POMC-expressing cells in the hypothalamus. Diabetes. 2016;65(3):673-86. https://doi.org/10.2337/ db15-0008.

32. Bombassaro B, Ramalho AFS, Fioravante M, Solon C, Nogueira G, Nogueira PAS, et al. CD1 is involved in diet-induced hypothalamic inflammation in obesity. Brain Behav Immun. 2019;78:78-90. https://doi.org/10.1016/j.bbi.201 9.01.011.

33. Morari J, Anhe GF, Nascimento LF, de Moura RF, Razolli D, Solon C, et al. Fractalkine (CX3CL1) is involved in the early activation of hypothalamic inflammation in experimental obesity. Diabetes. 2014;63(11):3770-84. https://doi.org/10.2337/db13-1495.

34. Cooper-Kuhn CM, Kuhn HG. Is it all DNA repair? Methodological considerations for detecting neurogenesis in the adult brain. Brain Res Dev Brain Res. 2002;134(1-2):1321. https:/doi.org/10.1016/S0165-3806(01)00243-7.

35. Kempermann G, Gast D, Kronenberg G, Yamaguchi M, Gage FH. Early determination and long-term persistence of adult-generated new neurons in the hippocampus of mice. Development. 2003;130(2):391-9. https://doi. org/10.1242/dev.00203.

36. Schindelin J, Arganda-Carreras I, Frise E, Kaynig V, Longair M, Pietzsch T, et al. Fiji: an open-source platform for biological-image analysis. Nat Methods. 2012;9(7):676-82. https://doi.org/10.1038/nmeth.2019.

37. Guillery RW, Herrup K. Quantification without pontification: choosing a method for counting objects in sectioned tissues. J Comp Neurol. 1997; 386(1):2-7. https://doi.org/10.1002/(SICI)1096-9861(19970915)386:1<2::AIDCNE2>3.0.CO;2-6.

38. Gilmore CP, DeLuca GC, Bo L, Owens T, Lowe J, Esiri MM, et al. Spinal cord neuronal pathology in multiple sclerosis. Brain Pathol. 2009;19(4):642-9. https://doi.org/10.1111/j.1750-3639.2008.00228.x.

39. Stuart T, Butler A, Hoffman P, Hafemeister C, Papalexi E, Mauck WM 3rd, et al. Comprehensive integration of single-cell data. Cell. 2019;177(7):1888902 e21. https://doi.org/10.1016/j.cell.2019.05.031.

40. Hafemeister C, Satija R. Normalization and variance stabilization of singlecell RNA-seq data using regularized negative binomial regression. Genome Biol. 2019;20(1):296. https://doi.org/10.1186/s13059-019-1874-1.

41. Eling N, Richard AC, Richardson S, Marioni JC, Vallejos CA. Correcting the mean-variance dependency for differential variability testing using singlecell RNA sequencing data. Cell Syst. 2018;7(3):284-94 e12. https://doi.org/1 0.1016/j.cels.2018.06.011

42. Lazic SE, Clarke-Williams CJ, Munafo MR. What exactly is ' $N$ ' in cell culture and animal experiments? PLoS Biol. 2018;16(4):e2005282. https://doi.org/1 0.1371/journal.pbio.2005282.

43. Razolli DS, Moura-Assis A, Bombassaro B, Velloso LA. Hypothalamic neuronal cellular and subcellular abnormalities in experimental obesity. Int J Obes (Lond). 2019;43(12):2361-9. https://doi.org/10.1038/s41366-01 9-0451-8.

44. Dragano NR, Monfort-Pires M, Velloso LA. Mechanisms mediating the actions of fatty acids in the hypothalamus. Neuroscience. 2020;447:15-27. https://doi.org/10.1016/j.neuroscience.2019.10.012.

45. Sidarta-Oliveira D, Jara CP, Ferruzzi AJ, Skaf MS, Velander WH, Araujo EP, et al. SARS-CoV-2 receptor is co-expressed with elements of the kininkallikrein, renin-angiotensin and coagulation systems in alveolar cells. Sci Rep. 2020;10(1):19522. https://doi.org/10.1038/s41598-020-76488-2.

46. Campbell JN, Macosko EZ, Fenselau H, Pers TH, Lyubetskaya A, Tenen D, et al. A molecular census of arcuate hypothalamus and median eminence cell types. Nat Neurosci. 2017;20(3):484-96. https://doi.org/10.1038/nn.4495.

47. Vallejos CA, Marioni JC, Richardson S. BASiCS: Bayesian analysis of single-cell sequencing data. PLoS Comput Biol. 2015;11(6):e1004333. https://doi.org/1 0.1371/journal.pcbi.1004333.

48. Recabal A, Caprile T, Garcia-Robles MLA. Hypothalamic neurogenesis as an adaptive metabolic mechanism. Front Neurosci. 2017;11:190,

49. Souza GF, Solon C, Nascimento LF, De-Lima-Junior JC, Nogueira G, Moura R, et al. Defective regulation of POMC precedes hypothalamic inflammation in diet-induced obesity. Sci Rep. 2016;6(1):29290. https://doi.org/10.1038/srep2 9290.

50. Spinelli M, Fusco S, Mainardi M, Scala F, Natale F, Lapenta R, et al. Brain insulin resistance impairs hippocampal synaptic plasticity and memory by increasing GluA1 palmitoylation through FoxO3a. Nat Commun. 2017;8(1): 2009. https://doi.org/10.1038/s41467-017-02221-9.

51. Melo HM, Seixas da Silva GDS, Sant'Ana MR, Teixeira CVL, Clarke JR, Miya Coreixas VS, et al. Palmitate is increased in the cerebrospinal fluid of humans with obesity and induces memory impairment in mice via proinflammatory TNF-alpha. Cell Rep. 2020;30:2180-2194 e8.

52. Ohta S, Misawa A, Lefebvre V, Okano H, Kawakami Y, Toda M. Sox6 upregulation by macrophage migration inhibitory factor promotes survival and maintenance of mouse neural stem/progenitor cells. PLoS One. 2013; 8(9):e74315. https://doi.org/10.1371/journal.pone.0074315. 
53. Wegner M, Stolt CC. From stem cells to neurons and glia: a Soxist's view of neural development. Trends Neurosci. 2005;28(11):583-8. https://doi.org/1 0.1016/j.tins.2005.08.008.

54. Zhang J, Jiao J. Molecular miomarkers for embryonic and adult neural stem cell and neurogenesis. Biomed Res Int. 2015;2015:727542.

55. Ge S, Goh EL, Sailor KA, Kitabatake Y, Ming GL, Song H. GABA regulates synaptic integration of newly generated neurons in the adult brain. Nature. 2006:439(7076):589-93. https://doi.org/10.1038/nature04404.

56. Ray J, Gage FH. Spinal cord neuroblasts proliferate in response to basic fibroblast growth factor. J Neurosci. 1994;14(6):3548-64. https://doi.org/10.1 523/JNEUROSCI.14-06-03548.1994

57. Ray J, Peterson DA, Schinstine M, Gage FH. Proliferation, differentiation, and long-term culture of primary hippocampal neurons. Proc Natl Acad Sci U S A. 1993;90(8):3602-6. https://doi.org/10.1073/pnas.90.8.3602

58. Reynolds BA, Weiss S. Generation of neurons and astrocytes from isolated cells of the adult mammalian central nervous system. Science. 1992; 255(5052):1707-10. https://doi.org/10.1126/science.1553558.

59. Song HJ, Stevens CF, Gage FH. Neural stem cells from adult hippocampus develop essential properties of functional CNS neurons. Nat Neurosci. 2002: 5(5):438-45. https://doi.org/10.1038/nn844.

60. Barnea A, Nottebohm F. Seasonal recruitment of hippocampal neurons in adult free-ranging black-capped chickadees. Proc Natl Acad Sci U S A. 1994; 91(23):11217-21. https://doi.org/10.1073/pnas.91.23.11217.

61. Kornack DR, Rakic P. Continuation of neurogenesis in the hippocampus of the adult macaque monkey. Proc Natl Acad Sci U S A. 1999;96(10):5768-73. https://doi.org/10.1073/pnas.96.10.5768.

62. Rochefort C, Gheusi G, Vincent JD, Lledo PM. Enriched odor exposure increases the number of newborn neurons in the adult olfactory bulb and improves odor memory. J Neurosci. 2002;22(7):2679-89. https://doi.org/10.1 523/JNEUROSCI.22-07-02679.2002

63. de Araujo TM, Velloso LA. Hypothalamic IRX3: a new player in the development of obesity. Trends Endocrinol Metab. 2020;31(5):368-77. https://doi.org/10.1016/j.tem.2020.01.002.

64. Friedman J. The long road to leptin. J Clin Invest. 2016;126(12):4727-34. https://doi.org/10.1172/JCl91578.

65. Lam TK, Schwartz GJ, Rossetti L. Hypothalamic sensing of fatty acids. Nat Neurosci. 2005;8(5):579-84. https://doi.org/10.1038/nn1456.

66. Niswender KD, Baskin DG, Schwartz MW. Insulin and its evolving partnership with leptin in the hypothalamic control of energy homeostasis. Trends Endocrinol Metab. 2004:15(8):362-9. https://doi.org/10.1016/j.tem.2004.07.009.

67. Cavadas C, Aveleira CA, Souza GF, Velloso LA. The pathophysiology of defective proteostasis in the hypothalamus - from obesity to ageing. Nat Rev Endocrinol. 2016;12(12):723-33. https://doi.org/10.1038/nrendo.2016.107.

68. Ignacio-Souza LM, Bombassaro B, Pascoal LB, Portovedo MA, Razolli DS, Coope $A$, et al. Defective regulation of the ubiquitin/proteasome system in the hypothalamus of obese male mice. Endocrinology. 2014;155(8):2831-44. https://doi.org/10.1210/en.2014-1090.

69. Moraes JC, Coope A, Morari J, Cintra DE, Roman EA, Pauli JR, et al. High-fat diet induces apoptosis of hypothalamic neurons. PLoS One. 2009:4(4):e5045. https://doi.org/10.1371/journal.pone.0005045.

70. Yan J, Zhang H, Yin Y, Li J, Tang Y, Purkayastha S, et al. Obesity- and aginginduced excess of central transforming growth factor-beta potentiates diabetic development via an RNA stress response. Nat Med. 2014;20(9): 1001-8. https://doi.org/10.1038/nm.3616.

71. Yi CX, Walter M, Gao Y, Pitra S, Legutko B, Kalin S, et al. TNFalpha drives mitochondrial stress in POMC neurons in obesity. Nat Commun. 2017;8(1): 15143. https://doi.org/10.1038/ncomms15143.

72. Cai D. Neuroinflammation and neurodegeneration in overnutrition-induced diseases. Trends Endocrinol Metab. 2013;24(1):40-7. https://doi.org/10.1016/j. tem.2012.11.003.

73. Goodman T, Hajihosseini MK. Hypothalamic tanycytes-masters and servants of metabolic, neuroendocrine, and neurogenic functions. Front Neurosci. 2015;9:387.

74. Sousa-Ferreira L, de Almeida LP, Cavadas C. Role of hypothalamic neurogenesis in feeding regulation. Trends Endocrinol Metab. 2014;25(2): 80-8. https://doi.org/10.1016/j.tem.2013.10.005.

75. Wallenius V, Wallenius K, Ahren B, Rudling M, Carlsten H, Dickson SL, et al. Interleukin-6-deficient mice develop mature-onset obesity. Nat Med. 2002; 8(1):75-9. https://doi.org/10.1038/nm0102-75.
76. Schobitz B, Voorhuis DA, De Kloet ER. Localization of interleukin 6 mRNA and interleukin 6 receptor mRNA in rat brain. Neurosci Lett. 1992;136(2): 189-92. https://doi.org/10.1016/0304-3940(92)90046-A.

77. Stark R, Grzelak M, Hadfield J. RNA sequencing: the teenage years. Nat Rev Genet. 2019;20(11):631-56. https://doi.org/10.1038/s41576-019-0150-2.

78. Campbell IL, Erta M, Lim SL, Frausto R, May U, Rose-John S, et al. Transsignaling is a dominant mechanism for the pathogenic actions of interleukin-6 in the brain. J Neurosci. 2014;34(7):2503-13. https://doi.org/10.1 523/JNEUROSCI.2830-13.2014

79. Koo BK, Kim EK, Choi H, Park KS, Moon MK. Decreasing trends of the prevalence of diabetes and obesity in Korean women aged 30-59 years over the past decade: results from the Korean National Health and Nutrition Examination Survey, 2001-2010. Diabetes Care. 2013;36(7):e95-6. https://doi. org/10.2337/dc13-0247.

80. Locke AE, Kahali B, Berndt SI, Justice AE, Pers TH, Day FR, et al. Genetic studies of body mass index yield new insights for obesity biology. Nature. 2015;518(7538):197-206. https://doi.org/10.1038/nature14177.

81. Levin BE. Arcuate NPY neurons and energy homeostasis in diet-induced obese and resistant rats. Am J Physiol. 1999;276(2):R382-7. https://doi.org/1 0.1152/ajpregu.1999.276.2.R382.

82. Strandberg L, Mellstrom D, Ljunggren O, Grundberg E, Karlsson MK, Holmberg AH, et al. IL6 and IL1B polymorphisms are associated with fat mass in older men: the MrOS Study Sweden. Obesity (Silver Spring). 2008; 16:710-3.

83. Balasubramaniam B, Carter DA, Mayer EJ, Dick AD. Microglia derived IL-6 suppresses neurosphere generation from adult human retinal cell suspensions. Exp Eye Res. 2009;89(5):757-66. https://doi.org/10.1016/j.exer.2 009.06.019.

84. Oh J, McCloskey MA, Blong CC, Bendickson L, Nilsen-Hamilton M, Sakaguchi DS. Astrocyte-derived interleukin-6 promotes specific neuronal differentiation of neural progenitor cells from adult hippocampus. J Neurosci Res. 2010;88(13):2798-809. https://doi.org/10.1002/jnr.22447.

85. Long Q, Upadhya D, Hattiangady B, Kim DK, An SY, Shuai B, et al. Intranasal MSC-derived A1-exosomes ease inflammation, and prevent abnormal neurogenesis and memory dysfunction after status epilepticus. Proc Natl Acad Sci U S A. 2017;114(17):E3536-E45. https://doi.org/10.1073/pnas.1703 920114

86. Haan N, Goodman T, Najdi-Samiei A, Stratford CM, Rice R, El Agha E, et al. Fgf10expressing tanycytes add new neurons to the appetite/energy-balance regulating centers of the postnatal and adult hypothalamus. J Neurosci. 2013;33(14):6170-80 https:/doi.org/10.1523/JNEUROSCI.2437-12.2013.

87. Lee DA, Bedont JL, Pak T, Wang H, Song J, Miranda-Angulo A, et al. Tanycytes of the hypothalamic median eminence form a diet-responsive neurogenic niche. Nat Neurosci. 2012;15(5):700-2. https://doi.org/10.1038/ nn.3079.

88. Oh DY, Talukdar S, Bae EJ, Imamura T, Morinaga H, Fan W, et al. GPR120 is an omega-3 fatty acid receptor mediating potent anti-inflammatory and insulin-sensitizing effects. Cell. 2010;142(5):687-98. https://doi.org/10.1016/j. cell.2010.07.041.

89. Wu Y, Patchev AV, Daniel G, Almeida OF, Spengler D. Early-life stress reduces DNA methylation of the Pomc gene in male mice. Endocrinology. 2014;155(5):1751-62. https://doi.org/10.1210/en.2013-1868.

90. Brown JP, Couillard-Despres S, Cooper-Kuhn CM, Winkler J, Aigner L, Kuhn HG. Transient expression of doublecortin during adult neurogenesis. J Comp Neurol. 2003:467(1):1-10. https://doi.org/10.1002/cne.10874.

91. Kuwabara T, Hsieh J, Muotri A, Yeo G, Warashina M, Lie DC, et al. Wntmediated activation of NeuroD1 and retro-elements during adult neurogenesis. Nat Neurosci. 2009;12(9):1097-105. https://doi.org/10.1038/ $\mathrm{nn} 2360$.

\section{Publisher's Note}

Springer Nature remains neutral with regard to jurisdictional claims in published maps and institutional affiliations. 